\title{
EVALUATION OF VARIOUS FLUID-FILM MODELS FOR USE IN THE ANALYSIS OF SQUEEZE FILM DAMPERS WITH A CENTRAL GROOVE
}

\author{
CC Siew, M Hill" and R Holmes \\ Mechanical Engineering, School of Engineering Sciences, \\ University of Southampton, Southampton SO17 1BJ, UK \\ *Corresponding Author: Martyn Hill (Email: M.Hill@soton.ac.uk, Tel: 02380-593075, Fax: 02380-593053)
}

\begin{abstract}
Experimental vibration responses of squeeze film dampers (SFDs) are obtained with four different central groove depths, two types of lubricant and various unbalance levels. Highly non-linear fluid stiffness and damping are observed, the damping being sensitively related to oil viscosity and unbalance. Existing oil film models are applied to predict the SFD behaviour. A special groove-two land model is able to predict the vibration behaviour of a very shallow grooved SFD and the conventional two-land theory is applicable to a SFD with a very deep groove. These observations provide useful guidelines for designing a shallow or deep grooved SFD-rotor assembly.
\end{abstract}

Keywords: Squeeze film damper, rotor dynamic, oil film bearing, vibration response

\section{NOTATIONS}
$A_{1} \quad$ parameter defined by equation (5c)
C $\quad$ SFD radial clearance (m)
$C_{g} \quad$ SFD circumferential groove depth (including the SFD radial clearance) (m)
$C_{g} / C \quad$ groove-depth to radial clearance ratio
C damping coefficient $(\mathrm{Ns} / \mathrm{m})$
$C_{r, \theta}$
damping coefficients in radial $(r)$ and tangential $(\theta)$ directions $\left(\frac{F_{r, \theta}}{\omega C \varepsilon}, \mathrm{Ns} / \mathrm{m}\right)$
D $\quad$ bearing diameter (m)
$d_{1,2,3,4} \quad$ correction factors for fluid forces coefficients defined by equation (4c)
$e_{d} \quad$ SFD eccentricity (m)
$F_{a} \quad$ applied unbalance force of the non-rotating SFD (N) 


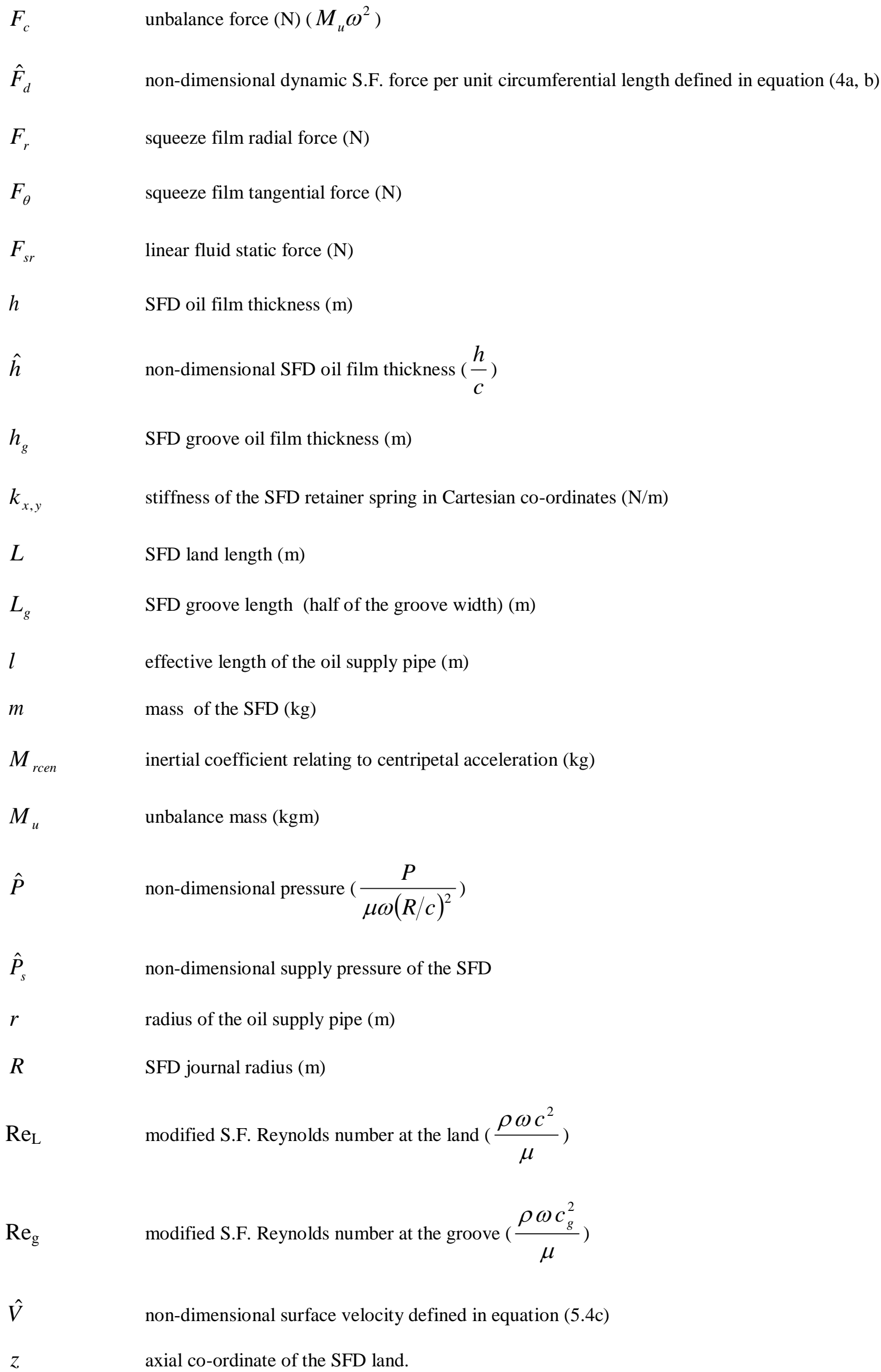


non-dimensional axial co-ordinate in the SFD land $\left(\frac{Z}{L}\right)$

Z

$\omega$

$\omega_{n}$

$\frac{\omega}{\omega_{n}}$

$\varepsilon$

$\mu$

$\lambda_{j k}$

$\hat{\lambda}_{j k}$

$\theta$

$\alpha$

$\beta$

$\sigma$

$\tau$

$\xi$

$\rho$

$(')$

$(\bullet)$

$\left({ }^{\wedge}\right)$ oil pipe flow resistance

shaft velocity (rad/s)

natural frequency of the shaft $(\mathrm{rad} / \mathrm{s})$

frequency ratio

dynamic eccentricity ratio of the SFD $\left(\frac{e_{d}}{c}\right)$

oil viscosity (Pa-s)

receptance at position $j$ due to a harmonic force at $k(\mathrm{~m} / \mathrm{N})$

non-dimensional receptance $\left(\lambda_{j k} m \omega^{2}\right)$

circumferential co-ordinate from the position of maximum film thickness

attitude angle measured in direction of unbalance force rotation

parameter defined by equation (5c) $\left(\frac{C}{C_{g}}\right)$

length ratio $\left(\frac{L_{g}}{L}\right)$

thickness ratio $\left(\frac{\hat{h}}{\hat{h}_{g}}\right)$

non-dimensional parameter defined by equation (4c)

density of oil $\left(\mathrm{kg} / \mathrm{m}^{3}\right)$

$$
\frac{d}{d(\omega t)}
$$

$\frac{d}{d(t)}$

non-dimensional variables 


\section{Introduction}

Squeeze film dampers (SFDs) are frequently used for the stabilization and vibration control of high speed rotating machines such as gas turbine engines and turbochargers. The oil-feeding groove within the SFD radial clearance is designed to prevent starvation of oil in the oil film. The pressure generated by the groove is traditionally neglected. Experimental evidence [1, 2, 3] has been found that the pressure produced in the groove relates to its depth, the shaft speed, the vibration amplitude at the SFD and the supply pressure. Various approaches have been demonstrated to tackle the problem particularly for SFDs with central grooves, such as those which consider the groove as a special damper land by using the simplified Navier-Stokes equations [3], those which use the fluid continuity theory to generate a more comprehensive model where the oil supply mechanism is taken into account [4] and those that include fluid compressibility in the Reynolds equation but only take due account of the low dynamic eccentricity ratio case [1]. The fluid damping, stiffness and inertia coefficients estimated by these models have been compared with the experimental measurements obtained from separate experimental rigs tested under restricted conditions and some agreement has been achieved. To date, no attempts have been made to assess the merits and weaknesses of each of these existing models when they are used to model a SFD with a wider range of parameters. Experimental support for these models in the vibration responses of rotor-SFD assemblies is also rare.

This paper investigates the dynamic responses of SFDs with central grooves only. Three possible fluid-film models are considered: those due to Holmes and Box [5], Tan et al. [3] and Zhang et al. [4]. The vibration responses predicted with the aid of each of these models are compared with the measured responses from two test rigs, namely:

1. A non-rotating unsealed squeeze film damper, which is excited by two electromagnetic shakers in the horizontal and vertical directions. This rig has been used for squeeze film force identification $[6,7,8]$ and has a similar configuration to those found in the experimental facilities mentioned in Tan et al. [3] and Zhang and Roberts. [4]. The damper is lubricated by 0.015 Pa-s and 0.006 Pa-s oil with groove depth-toclearance ratios of 3.27 and 10.09 .

2. A flexible shaft-unsealed sprung SFD assembly, which has been discussed in references [9, 10, 11, 12]. The vibration responses of the system excited by various values of unbalance mass added at an overhung disk were measured. The SFD with a groove depth-to-clearance ratio of 16.15 was initially tested with oil of 
0.006 Pa-s viscosity. The groove was then deepened to have a 40.77 groove depth-to-clearance ratio and tested with 0.006 Pa-s and 0.015 Pa-s oil.

Over the years, various investigations have been carried out separately to examine SFD vibration responses using different experimental rigs. However, work to summarise the distinct features of these experimental data has yet to be conducted. Furthermore, the experimental and theoretical analyses reported by other researchers mainly concern the study of the SFD with a relatively shallow groove, which usually has a groove depth-toclearance ratio between 2-10. Current work has extended this value to about 40 to observe a wider operating parameter range, intended to find a better correlation between the different theoretical models and experimental measurements.

\section{Theoretical models}

To date, four main approaches have been developed to model the flow interactions between the oil feeding groove and the squeeze film lands $[1,3,4,5]$. In this paper, three models are selected to compare their predictions with the experimental results measured from the test rigs and they are: Model 1: The conventional Reynolds Equation [5], Model 2: The Lubricant Supply Mechanism (LSM)-Centrally Grooved Short SFD Model by Zhang and Roberts [4] and Model 3: A Special Groove-Two Film Lands Model by Tan et al. [3]. The model proposed by San Andres [1] is not considered in this paper as it only caters for low vibration SFDs, where as the vibration amplitudes measured from the current test rigs are up to 0.8 dynamic eccentricity ratio. It is also important to note that this work is designed to study the vibration behaviour of centrally grooved SFDs only.

\subsection{Model 1:The Conventional Reynolds Equation}

\section{A. The Two-Land Model}

The Reynolds equation [13], which is derived from the Navier-Stokes equations for incompressible flow conventionally forms the basis for calculating the pressure distribution within the oil film. The short bearing approximation is found to be appropriate for the case where the damper is fed from a central circumferential groove with $\mathrm{L} / \mathrm{D}<0.25$ [5]. Using this approximation, the pressure generated in the groove is assumed to be negligible compared to the supply pressure, and the pressure in each land is represented by a parabolic profile. 
Assuming a full oil film in the clearance and that the SFD journal centre orbit is concentric around the bearing centre ( $\dot{\varepsilon}=0, \dot{\alpha}=\omega$ ), the two oil film forces acting on the journal i.e. the radial force ( $F_{r}$ ) and the tangential force $\left(F_{\theta}\right)$ can be written (Fig.1a) as,

$F_{r}=0$

$F_{\theta}=\frac{2 \pi \mu R L^{3}}{c^{2}} \frac{\varepsilon \omega}{\left(1-\varepsilon^{2}\right)^{3 / 2}}$

\section{B. One-Land Model}

In some SFD applications, the groove can be made small either in depth or width. Therefore the non-linear squeeze forces may well be represented by a one-land model where the damper could be modelled as having one single land where its effective land length is equal to the sum of the two separate damper lands, ignoring the width of the groove. For a centrally grooved SFD with a circular journal-centre orbit, the radial and tangential forces are expressed as,

$F_{r}=0$

$F_{\theta}=\frac{\pi \mu R(2 L)^{3}}{c^{2}} \frac{\varepsilon \omega}{\left(1-\varepsilon^{2}\right)^{3 / 2}}$

One may note from equations (1a, b) and (2a, b) that the one-land model produces a pair of squeeze film forces which are 4 times greater than those generated by the two-land model.

\section{A Complete SFD Width Model}

A shallow, centrally grooved SFD may alternatively be modelled as having an effective land length of $2\left(L_{g}+L\right)$

(Fig.1), i.e. the complete width of the SFD. Applying this assumption results in the following forms for the full circular orbiting squeeze film forces,

$F_{r}=0$

$F_{\theta}=\frac{\pi \mu R\left(2 L+2 L_{g}\right)^{3}}{c^{2}} \frac{\varepsilon \omega}{\left(1-\varepsilon^{2}\right)^{3 / 2}}$ 
The inadequacies of these conventional models in simulating the squeeze film forces within a damper having various groove depths and supply pressures have been extensively reported. However, due to the lack of a comprehensive squeeze film force model, the present work aims to establish whether such models are still applicable under certain limited conditions. These findings should enable the effects of the known parameters such as the land length ( $L$ ), journal radius ( $R$ ), oil viscosity $(\mu)$ and radial clearance ( $C$ ) to be taken into account more accurately in an actual rotor-bearing design.

\subsection{Model 2: The Lubricant Supply Mechanism (LSM)-Centrally Grooved Short SFD Model}

The non-linear oil film force of a centrally grooved unsealed SFD was investigated by Zhang and Roberts [4] using an integrated theory which takes into account the pressure difference between the inlet of the oil pipe and the inlet of the groove, caused by the flow resistance in the oil pipe. In their work, a laminar incompressible Newtonian lubricant was assumed and no cavitation effect was included. Following the conventional assumptions, the SFD was considered to be short and the parabolic velocity profile in the fluid film to be not significantly distorted by any fluid inertia effect. This model gave a significant improvement in predicting the damping coefficient of the SFD.

This model also led to the prediction of a nonzero fluid static stiffness, which is a characteristic of hydrostatic bearings, where deep recesses and orifices around the bearing housing are the sources of this stiffness [14, 15, 16]. For SFDs to cope effectively with direction-changing loads, a circumferential groove together with equally spaced oil feeding holes and tubes around the bearing housing, may produce a fluid static stiffness similar to that in hydrostatic bearings. It is also reported $[17,18,19]$ that the number of oil feeding holes around the SFD housing may affect the size and circularity of the damper orbits. Albeit with the absence of a circumferential groove, it has been demonstrated that as the number of oil holes increases (to 4), the difference between the maximum and minimum orbit displacements decreases, and the orbits tends to become more circular, with a slightly increased radius compared to zero hole orbits [18, 19].

The full oil film forces for a circular centered orbit, which were derived in equations (16) to (26) in reference [4] are now shown as follows with a slight modification in notation:

$$
\begin{aligned}
& F_{r}=-\frac{2 \mu \omega R L^{3}}{c^{2}} \int_{0}^{2 \pi} \hat{F}_{d} \cos \theta d \theta-F_{s r} \\
& F_{\theta}=-\frac{2 \mu \omega R L^{3}}{c^{2}} \int_{0}^{2 \pi} \hat{F}_{d} \sin \theta d \theta
\end{aligned}
$$


where

$$
\begin{aligned}
& F_{s r}=\frac{2 \mu \omega R L^{3}}{c^{2}}\left[3(1+2 \sigma) \hat{P}_{s} \int_{0}^{2 \pi} \frac{\cos \theta}{\xi} d \theta\right] \\
& \bar{F}_{d}=-\left(\frac{L}{R}\right)^{3}\left\{\frac{1}{\hat{h}^{3}} d_{1} \hat{V}+d_{2} \hat{P}_{s} \hat{h} \operatorname{Re} \hat{V}-\frac{\operatorname{Re}}{5 \hat{h}^{2}} d_{4} \hat{V}^{2}\right\} \\
& \hat{V}=\varepsilon \omega \sin \theta \\
& d_{1}=4+3\left\{4 \sigma(1+\sigma)-\frac{1-4 \sigma(1+\sigma)}{\xi}\right\} \\
& d_{2}=\frac{3}{5 \xi}\left\{\left(1+2 \sigma+\sigma^{2}\right)-\frac{9+22 \sigma+8 \sigma^{2}}{4 \xi}+\frac{16+14 \sigma+4 \sigma^{2}+5 \sigma \tau-\tau^{2}}{4 \xi^{2}}\right\} \\
& d_{3}=4+3\left\{4 \sigma(1+\sigma)-\frac{2+8 \sigma+8 \sigma^{2}}{\xi}+\frac{1+4 \sigma+4 \sigma^{2}+\sigma \tau}{\xi^{2}}\right\} \\
& d_{4}=4+3\left\{4 \sigma(1+\sigma)-\frac{13+52 \sigma+58 \sigma^{2}}{4 \xi}+\frac{14+59 \sigma+5 \sigma \tau+68 \sigma^{2}}{4 \xi^{2}}-\frac{11+46 \sigma+52 \sigma^{2}+10 \sigma \tau-\tau^{2}}{8 \xi^{3}}\right\} \\
& \sigma=\frac{L_{g}}{L}, \quad \tau=\frac{\hat{h}^{2}}{\hat{h}_{g}}, \quad \xi=1+\frac{Z c^{3} \hat{h}^{3}}{12 \mu L}, \quad Z=\frac{32 \mu R l}{3 r^{4}}, \quad \operatorname{Re}=\frac{\rho \omega c^{2}}{\mu}, \quad \hat{P}_{s}=\frac{P_{s} c^{2}}{6 \mu \omega L^{2}}
\end{aligned}
$$

This set of equations shows that the static fluid force $\left(F_{s r}\right)$ increases the radial squeeze film force due to the consideration of the oil pipe flow resistance $(Z)$ which is a function of the length $(l)$ and the radius $(r)$ of the supply pipes. It was also suggested that the inertia coefficient $M_{\text {rcen }}$ (added hydrodynamic mass) of a full film concentric SFD could be estimated using the following equation,

$$
M_{\text {rcen }}=\frac{2 \rho R L^{3}}{c}\left(\frac{1}{12} \int_{0}^{2 \pi} \frac{d_{3} \cos ^{2} \theta}{\hat{h}} d \theta+\frac{\varepsilon}{5} \int_{0}^{2 \pi} \frac{d_{4} \sin ^{2} \theta \cos \theta}{\hat{h}} d \theta\right)
$$

\subsection{Model 3: A Special Groove-Two Film Lands Model}

A study of the effect of the circumferential groove on the dynamic behaviour of an SFD was carried out by Tan et al. [3]. In the study, the groove was modelled as a special damper using linearised Navier-Stokes equations to consider the variations of fluid velocity and pressure, whereas the relatively small inertia effects produced by the oil within the two short damper lands were predicted by simplified conventional Navier-Stokes equations. The two parts of the analysis were combined by continuity conditions to study the interactions of the flow and the pressure between the film lands and the groove, resulting in a new model for a full film concentric SFD. The 
tangential and radial forces of the new model were extracted from equations (46) and (47) in reference [3] and presented as the following equations with minor changes in notation, (subscript $g$ refer to the parameters within the groove region),

$$
\begin{aligned}
& F_{r}=\frac{\mu \omega R\left(2 L+2 L_{g}\right)^{3}}{c^{2}} \frac{\varepsilon}{2} \operatorname{Re} \frac{I_{1}^{02}}{12}+\varepsilon \frac{I_{2}^{21}}{5} \frac{2+3 \sigma}{(1+\sigma)^{3}} \\
& F_{\theta}=\frac{\mu \omega R\left(2 L+2 L_{g}\right)^{3}}{c^{2}} \frac{\varepsilon}{2} I_{3}^{20} \frac{2+3 \sigma+3 A_{1} \sigma(1+2 \sigma)}{(1+\sigma)^{3}}
\end{aligned}
$$

where

$$
\begin{aligned}
& I_{1}^{02}=\frac{2 \pi}{\varepsilon^{2}}\left(\frac{1}{s}-1\right), \quad I_{2}^{21}=\frac{2 \pi}{s \varepsilon^{3}}\left(2 s-2+\varepsilon^{2}\right)^{1 / 2}, \quad I_{3}^{20}=\frac{\pi}{s^{3}} \\
& S=\left(1-\varepsilon^{2}\right)^{1 / 2}, \quad A_{1}=\frac{\beta^{2}(3-2 \beta)}{1+\left(\frac{\mathrm{Re}}{10 \beta^{2}}\right)^{2}} \\
& \beta=\frac{c}{c_{g}}, \quad \operatorname{Re}=\frac{\rho \omega c^{2}}{\mu}, \sigma=\frac{L_{g}}{L}
\end{aligned}
$$

The predictions of this theory were tested using experimental results obtained from a test rig in reference [4] which had a groove depth-to-clearance ratio $\left(c_{g} / c\right)$ of about 3.37. It was reported that this model gave better correlation with the experimental data than those generated by the conventional theory explained in section 2.1.

\section{Experimental Facilities}

The vibration responses measured from two different test rigs are presented below and the test facilities are briefly explained as follows,

\subsection{Test Rig No. 1: A non-rotating SFD with electro-magnetic shaker}

The non-rotating SFD (Fig.2) tested in this work has a similar configuration (see Tables 1 and 2) i.e. dimensions, oil supply conditions and force excitation methods found in the test facilities used by Zhang \& Roberts [4] and Tan et al. [3], who developed Models 2 and 3 respectively. As a result, it is interesting to compare the observations obtained in this work with the conclusions drawn in references [3] and [4].

The test rig was developed to study the SFD alone, without the further complications of a rotating shaft and bearings. The SFD is mounted on a non-rotating beam, which in turn is clamped in two sliding support brackets 
at its ends. The effective length of the beam can be changed by varying the positions of the support brackets as a result altering the system natural frequency. Oil is supplied at three locations, evenly spaced around the SFD circumference. The oil supply pressure is measured using a static gauge situated in the main supply line. (The dimensions of the damper and supply conditions are shown in Tables 1 and 2.) The damper journal is subjected to a constant rotating force produced by two electro-magnetic shakers lying in horizontal (x) and vertical (y) planes to simulate the out of balance force of a rotating system. The shakers are fed with two signals which are $90^{\circ}$ out of phase with each other but of the same amplitude, from a variable phase low frequency generator and power amplifier. The combination of the two forces gives a constant force rotating at the frequency of the input signal. Thus the orbits of the damper journal should be circular, having a constant dynamic eccentricity about the central axis.

Assuming the structure is vibrating in a single mode and that the static eccentricity of the SFD is zero, a closed form solution of the steady state equations of motion can be derived by assuming circular centred orbits. Hence, the equations of motion for the test rig journal shown in Fig.2 can be written as [8],

$$
\begin{aligned}
& F_{a} \cos (\omega t-\alpha)-F_{r}-k c \varepsilon=-m c \varepsilon \omega^{2} \\
& F_{a} \sin (\omega t-\alpha)-F_{\theta}=0
\end{aligned}
$$

Eliminating the sine and cosine terms, we have

$$
\left(k c \varepsilon+F_{r}-m c \varepsilon \omega^{2}\right)^{2}+F_{\theta}^{2}=F_{a}^{2}
$$

Equation (7) can be easily solved by a root finding numerical method (e.g. the bisection method) to find the eccentricity ratio $(\varepsilon)$. The tangential and radial forces derived from the various models discussed in the previous section are inserted to compute the forced response of the SFD with the dimensions shown in Table 1.

The SFD was tested under the conditions shown in Table 2 and the experimental results were taken when the rig reached its equilibrium temperature of between $32^{\circ} \mathrm{C}$ and $34^{\circ} \mathrm{C}$. More details of the experimental facilities can be found in references $[6,7,8]$. 


\subsection{Test Rig No. 2: A Flexible Shaft-SFD Assembly}

Fig.3 shows the schematic diagram of the test facility of a flexible shaft provided with an unsealed SFD. The rig consists of a stepped shaft supported on two bearings, one of which is self-aligning and the other flexibly mounted on four support bars ( $k=123.4 \times 10^{3} \mathrm{~N} / \mathrm{m}$ ) via a damper ring. At the far end of the shaft an overhung disk is attached. One of several unbalance masses can be screwed into the overhung disk for excitation purposes. The shaft is driven by an induction motor through a timing belt, drive shaft and flexible coupling. The shaft has a main cross sectional diameter of $50 \mathrm{~mm}$, stepped section diameter of $25 \mathrm{~mm}$ and a total length of $1.3 \mathrm{~m}$. The open-ended SFD has the dimensions shown in Table 3. This configuration has been tested experimentally in previous work $[9,10,11,12]$ and shown to have two undamped natural frequencies at about 14 and $41 \mathrm{~Hz}$. Displacement at the SFD position was measured in the $x$ and $y$ directions using a pair of proximity displacement transducers. The shaft was tested under the conditions shown in Table 4. Details of the data acquisition system can be found in [11, 12].

The flexible shaft is modelled as 41 pin-jointed lumped masses using the Modified Iteration Method presented in reference [12]. According to an analysis suggested by Thompson [20], the gyroscopic effect at the overhung disk for the system studied is small and therefore is assumed to be negligible. If the SFD is assumed to be concentric, the equations of motion at the damper position can be expressed in terms of receptances $(\lambda)$ as follows.

$$
\begin{gathered}
e_{d}=-\lambda_{d d} F_{r}+\lambda_{d c} F_{c} \cos \beta_{d} \\
0=\lambda_{d d} F_{\theta}+\lambda_{d c} F_{c} \sin \beta_{d}
\end{gathered}
$$

From equations (8a, b), we obtain

$$
\varepsilon=\frac{e}{c}=\frac{ \pm \sqrt{\left(\lambda_{d c} F_{c}\right)^{2}-\left(\lambda_{d d} F_{\theta}\right)^{2}}-\lambda_{d d} F_{r}}{c}
$$

Equation (9) is solved by the bisection method [21]. The unbalance responses at the SFD position are calculated and compared with the predictions of the available fluid film theories. 


\section{Results}

Six sets of experimental results measured from a concentric SFD mounted in the two test rigs are discussed. The average values of the $\mathrm{x}$ and $\mathrm{y}$ eccentricity ratios measured at a number of unbalance force frequencies [Test rig no.1: non-rotating SFD] or steady-state rotor speeds [Test rig no. 2: flexible shaft-SFD assembly] are plotted together with the predictions of various theoretical models (all $2 \pi$-film) in Figs. 4 to 9 (model numbers follow the headings outlined in section 2). The calculated response curves of Model 1c which considers a damper having an effective land length equal to a complete damper width are only shown in Figs.4a and 4b. According to the previous research, this model is expected to be applicable to a damper with a very shallow groove, i.e. the configuration found in Test no. 1 and therefore its prediction is omitted in Figs. 5 to 11 for a clear presentation.

The first point to make is that no single theoretical model is able to produce a good qualitative and quantitative agreement with all the experimental results. Each model has its own merits and weaknesses in modelling the response of a SFD excited under a particular set of conditions.

\subsection{Test Rig No.1: A non-rotating SFD with electro-magnetic shaker}

In Fig.4 the forced response of a very shallowly grooved SFD $\left(c_{g} / c=3.27\right)$ was tested with a lubricant of 0.015 Pa-s viscosity and two different applied unbalance forces (i.e. $25 \mathrm{~N}$ and $50 \mathrm{~N}$, Test no.1, Table 2). Both Figs.4a and b show that Model 3 fits the two experimental curves very well compared to the rest. It is apparent that the theoretical predictions of Models $1 \mathrm{~b}$ and $1 \mathrm{c}$ also give good qualitative agreement with those obtained experimentally. Their predictions are able to give upper and lower bound limits to the response produced by the SFD with such a shallow groove.

In Fig.5 the groove of the damper has been deepened to give $c_{g} / c=10.09$ (Test no.2, Table 2) and is tested under the same conditions as those shown in Fig.4. The eccentricity ratios of this configuration are notably higher than those measured from the shallowly grooved damper for all applied force frequencies. This is consistent with other experimental findings [2] where a greater groove depth reduced the damping generated by the oil squeezing effect within the groove. However, none of the models used in the current study is able to give good correlation with the test results. Although the two-land model (Model 1a) is generally good in calculating the qualitative trend of the test data, its predicted amplitudes are grossly in error especially in the higher forcing frequency region. 
Fig.6 shows the SFD response of the damper with the same groove depth as in Fig. 5 but the oil has been changed to a slightly lower viscosity with $\mu=0.006$ Pa-s (Test no.3, Table 2). With this thinner oil the resonance of the rig is clearly shown and located at about $33 \mathrm{~Hz}$, which is about $2 \mathrm{~Hz}$ higher than the measured natural frequency of the rig. This shift of resonance peak is probably caused by the static fluid stiffness [4] produced by the lubricant supplied with $68.95 \mathrm{kPa}$ pressure. It can be seen in the low frequency range of Figs.6a and $6 \mathrm{~b}$ that the amplitudes are lower than the predicted values of all the theoretical models which do not consider such an effect (i.e. all except Model 2). As mentioned in the previous section, Model 2 includes the influence of the oil supply mechanism which leads to the calculation of the static fluid force. However, present data show that such a model overestimates the magnitudes of SFD forces and hence does not make it more attractive than the other theoretical methods in computing the experimental response for the test results discussed so far.

Fig.6 also shows that the SFD used in Test no.3 is sensitive to the applied unbalance force. The vibration amplitudes are found to be closer to the one-land predictions (Model 1b) when the unbalance force is low $\left(F_{a}=\right.$ $20 \mathrm{~N}$ ) and conforms more to the two-land predictions (Model 1a) when a higher unbalance force was used ( $F_{a}=$ $40 \mathrm{~N}$ ). This was initially thought to be due to the occurrence of cavitation within the damper clearance. However an increase of supply pressure did not produce a significant effect on the vibration amplitude. A similar phenomenon was also reported by Holmes and Box [5] where the unbalanced response of their SFD tended toward that of the two-land model as the unbalance was increased. This is probably because larger vibration orbits resulting from the higher unbalance increase the pressure gradient between the groove and squeeze film lands. Consequently, the influence of the lands becomes more distinct. A more detailed report on the effects of unbalance on the pressure recorded at the edge of the groove and at the mid-land can also be found in the work of Levesley and Holmes [22] where a similar conclusion was drawn.

It is suspected that some amount of fluid static stiffness may be produced by the SFD used in Tests no. 2 and 3. Its possible effect is depicted in Fig. 7 where the experimental eccentricity ratios of the damper at very low forcing frequency ( $\omega \rightarrow 0$ ) are plotted against the applied unbalance force. The measured beam stiffness and the calculated static fluid stiffness of Model 2 are also shown. Fig.7a shows that for large applied force the low frequency experimental eccentricity ratios vary non-linearly with the applied unbalance forces. This suggests that the oil film may have produced a stiffness, which is non-linearly related to the eccentricity ratio. The oil film stiffness becomes apparent when the low frequency eccentricity ratio is higher than 0.7. As shown in Fig.7a, for the case when a $50 \mathrm{~N}$ applied unbalance force was introduced, about $42.8 \mathrm{kN} / \mathrm{m}$ static oil film stiffness was generated. This is about $16 \%$ higher than the measured linear beam stiffness. 
For the damper with a lower viscosity lubricant (0.006 Pa-s) and the beam with higher stiffness (Test no.3, Table 2), the static stiffness effect of the squeeze film is demonstrated in Fig. 7b. The experimental eccentricity ratios of the damper at low frequency are plotted against the applied unbalance force up to $40 \mathrm{~N}$. With such a thin oil and relatively low unbalance force excitation, the observed static oil stiffness is roughly linear. Comparing the measured beam stiffness with the total static stiffness observed in Test no.3, one can see that about $47.5 \%$ in static oil stiffness may have been added to the system. Referring also to Fig.6 where the dynamic responses of Test no.3 are shown, we find that this amount of apparent oil stiffness has possibly caused the shift in the resonance to a higher frequency compared to the expected system natural frequency at about $31 \mathrm{~Hz}$.

To gain more insight into the influence of the static oil stiffness on SFD response, Fig.8 shows the unbalance responses of the non-rotating SFD computed with some added stiffness determined from Fig.7 for Tests no. 2 and 3. The experimentally determined total stiffness at low frequency is inserted into Models 1 and 3 for further comparison (i.e. $k$ in equation (7) is replaced by the observed total static stiffness).

In Fig.7 it was found that oil film Model 2 greatly overestimated the oil static stiffness, resulting in large errors in predicting the vibration responses measured in Tests no. 1, 2 and 3 (see Figs.4, 5 and 6). In order to reexamine the dynamic force prediction using Model 2, the static fluid force $\left(F_{s r}\right)$ shown in equation (4a) was discarded and only the dynamic squeeze film forces were used as derived. Static oil film stiffness was taken into account by increasing $k$ in equation (7) to the value found in Fig. 7 (i.e. $k$ equal to the total of the measured beam stiffness and observed fluid static stiffness).

In Figs.8a and 8b it is shown that all the modified models, especially the one proposed by Zhang and Roberts (Model 2) have now been able to match the measured data more accurately throughout the frequency range. Under these conditions, the two-land pressure assumed in Model 1 is still grossly in error. However, when the unbalance force is increased and low viscosity oil is supplied (Fig.8c), the modified two-land damper prediction still gives a reliable estimate.

These figures suggest that the oil film forces may not have the relationship with unbalance and oil viscosity that has been assumed to date. This is consistent with Arauz and San Andres [23] who proposed that conceptually these forces should have non-linear stiffness $(K)$, mass $(M)$ and damping $(C)$ terms, which need to be identified and modelled accurately. 


\subsection{Test Rig No.2: A Flexible Shaft-SFD Assembly}

Fig. 9 illustrates the unbalance response of the sprung SFD supporting a flexible shaft (Fig.3) with two different values of unbalance added at the overhung disk (Test no.4, Table 4). No cavitation bubbles were observed within the operating speed range. The groove was about 16 times deeper than the radial SFD clearance. It is shown in the test results Figs.9a and $9 \mathrm{~b}$ that the damping provided by the groove cannot be neglected in the low speed range, i.e. at speeds which are close to the first undamped natural frequency of $14 \mathrm{~Hz}$. As the rotational speed approaches the second critical speed (40 rev/s), the vibration amplitudes increase and tend towards the two-land predictions (Model 1a).

The flexible shaft-sprung SFD assembly was then tested with a very deeply grooved damper having $c_{g} / c=40.77$. Two different lubricants were used, to correspond to typical aero-engine conditions, having viscosities of 0.006 Pa-s (Test no.5, Table 4) and 0.015 Pa-s (Test no.6, Table 4). Their respective unbalance responses are plotted in Figs.10 and 11. Under these test conditions, the SFD behaves very closely to a theoretical two-land damper (Model 1a) for most speeds, unbalance values and oil viscosities. Migration of resonant peaks either due to static fluid stiffness or fluid inertia effects was small.

\section{Possible sources of error}

The present work shows that the very shallowly grooved damper $\left(c_{g} / c=3.27\right)$ used in Test no.1 may be modelled using Model 3 and that the SFD with a very deep groove $\left(c_{g} / c=40.77\right.$ in tests no.5 and 6$)$ behaves more like a two-land damper as assumed in Model 1a. These findings could be useful guidelines for the designer who is dealing with a particular rotor-SFD application. However, some errors are observed between the theoretical predictions and the experimental measurements, particularly for the cases when the groove depth to clearance ratio is between 3 and 41 (Figs.5, 6 and 9). This may in part be due to the following reasons:

For ease of computation, the models proposed by Zhang \& Roberts (Model 2, [4]) and Tan et al. (Model 3, [3]) both assume a SFD having a small groove depth to clearance ratio, which is less than about 5 , so that a simplified form of the Navier-Stokes equation can be applied. As a result, we can see in Fig.12 that the radial $\left(C_{r}\right)$ and tangential $\left(C_{\theta}\right)$ force coefficients (which are calculated by equation (10)) for Model 3 only show a small change within the low $c_{g} / c$ region, i.e. $c_{g} / c=1 \sim 5$. This may explain why Model 3 can only give a good fit to the test results when a shallowly grooved damper is used, i.e. $c_{g} / c=3.27$ (Fig.4). 


$$
C_{r, \theta}=\frac{F_{r, \theta}}{\omega C \varepsilon}
$$

For Model 2, the change of force coefficient is more related to the value of supply pressure, particularly in the radial direction (Fig.12a). Model 2 overestimates the static force provided by the oil film (Figs.4, 5, 6, 9, 10 and 11) and for this reason becomes less able to predict the vibration responses in the test results studied in the present work (see also Fig.7). According to Zhang \& Roberts [4], the prediction of the static fluid force may be improved by taking into account the flow resistance of the connector between the feeding groove and the oil pipe, and the modelling of circumferential oil flow within the damper land and oil feeding groove. It is shown in Fig.8 that the accuracy of Model 2 may be improved so long as a good estimation of the static fluid force can be achieved.

Due to the complexity of solving a set of second order non-linear partial differential equations, the theoretical models investigated in this paper assume an oil film with low inertia effects. However, a large fluid inertia could well be introduced under certain circumstances and was recorded in references [24] and [25] when a sprung endchambered sealed damper (8 80 rev/s) and an unsprung open-ended SFD (8 200 rev/s) were tested on a rigid and flexible rotor respectively. Therefore an attempt was made to estimate the Reynolds number in the film land and in groove using the following expressions,

Reynolds number at the film land, $\operatorname{Re}_{L}=\frac{\rho \omega c^{2}}{\mu}$

Reynolds number at the oil groove, $\operatorname{Re}_{g}=\frac{\rho \omega c_{g}^{2}}{\mu}$

In addition, the fluid inertia coefficients $\left(M_{r c e n}\right)$ of the grooved SFDs are also calculated by substituting the experimental data into equation (4d) to give a rough indication of the added hydrodynamic mass. The results are shown in Table 5. For all the tests conducted in this work, the fluid inertia at the film lands is small $\left(\operatorname{Re}_{\mathrm{L}}\right.$ only varies between 0.01 to 2.1). At the groove, such an effect may be more profound because $\mathrm{Re}_{\mathrm{g}}$ may vary from 0.19 to a maximum value of $2.5 \times 10^{3}$ (Test No.5). 
A small shift of the experimental resonance peak to a lower frequency as compared to the two-land model prediction is observed in Test no. 2 (Fig. 5). This may have been induced by a fluid inertia effect at the oil groove which is about 10 times deeper than the SFD clearance. For this case, $\operatorname{Re}_{\mathrm{g}}$ varies between 1.79 to 62.86 and the added hydrodynamic mass may be up to $0.48 \mathrm{~kg}$ (about $4.7 \%$ of the effective damper journal mass).

It is also interesting to note in Table 5 that the $\mathrm{Re}_{\mathrm{g}}$ of Test No. 5 may be up to $2.5 \times 10^{3}$, although current findings suggest that the conventional inertialess two-land model (Model 1a) provides the best comparison with the experimental measurements (Fig.10). A possible explanation for this is the relatively small hydrodynamic mass (about $0.409 \sim 0.608 \mathrm{~kg}$ ) produced by the current damper compared to the total rotor/damper mass, which is 21.3 kg.

\section{Conclusions}

This paper assesses the efficacy of various theoretical methods available for use in the analysis of a circumferentially grooved squeeze film damper. Experimental data collected from two separate test rigs which have a groove depth-to-clearance ratio ranging from 3.27 to 40.77 were used for comparison so that a wider picture of the non-linear vibration response of the damper could be seen. The conclusions of the study are as follows,

1. Damper with a shallow groove $\left(c_{g} / c \leq 3.27\right)$ : The non-linear vibration response of this type of damper (Fig. 4) may be accurately modelled by Model 3 (that of Tan et al.) which takes into account the small inertia effects and flow interactions between the groove and the thin film land using the Simplified Navier Stokes Equation. It is found in this study that the damper with this groove depth does not fit the predictions of the one-land nor of the complete damper width model. These latter models are only able to provide upper and lower limits for the damper response.

2. Damper with an intermediate groove depth $\left(3.27<c_{g} / c<41\right)$ : None of the evaluated methods in this study is able to provide good predictions for the SFD's tested (Fig.5 and 6). It is found that the stiffness and damping effects generated by the oil squeezing motion within the damper clearance are highly nonlinear. Static oil stiffness as high as $47 \%$ of the structure stiffness is observed and is sensitively related to oil viscosity and unbalance (Fig.7). However when fluid static stiffness was estimated experimentally and added to the models, it was found that model 2 (that of Zhang \& Roberts) provided a good 
estimation for the case where a higher viscosity oil was applied (Fig.8a), but that with low viscosity oil and higher dynamic eccentricity ratio, the behaviour approaches that of the two-land model (model 1a).

3. Damper with a very deep groove $\left(c_{g} / c \geq 41\right)$ : Albeit with the SFD performance moderated by the flexible rotor, the experimental measurements (Fig.10 and 11) obtained from the flexible shaft-sprung SFD configuration suggest that the SFD with such a groove depth behaves very closely to the ideal twoland model, where the oil film effects in the supply groove can be neglected, implying that the deep groove uncouples the pressures between the two film lands and therefore that they can be modelled as two separate parabolic pressures under the various unbalance and oil viscosity conditions.

Some of the poor correlations of the applied theoretical models with the test data may be due to the fact that tested groove depths were much larger than permissible when using some of the models, failure to allow for large fluid inertia effects and flow resistance caused by the connectors between the oil feeding tubes and the holes. A more comprehensive mathematical model is needed but conclusions drawn from this paper, particularly those mentioned in 1 and 3 above, should be sufficient to provide useful guidelines to design a very shallowly or very deeply grooved SFD-rotor assembly with some degree of confidence.

\section{ACKNOWLEDGEMENT}

The authors would like to thank to Mr. P. Wheeler for his assistance in conducting the experiments.

\section{REFERENCES}

1. SanAndres L.A. Analysis of short squeeze film dampers with a central groove. ASME. Trans., J of Tribology, Oct 1992, vol.114, No.4, pp.659-665.

2. Arauz G.L and SanAndres L. Experimental force response of a grooved squeeze film damper. Tribology International. 1997, vol.30. No.1, pp.77-86.

3. Tan Qingchang, Chang Ying and Wang Lyjiang. Effect of a circumferential feeding groove on fluid force in short squeeze film dampers. Tribology International, 1997, vol.30, No.6, pp. 409-416. 
4. Zhang, J. X. and Roberts, J. B., Force coefficients for a centrally grooved short squeeze film damper. ASME Trans., J. Tribology, July 1996, vol.118, pp.608-616.

5. Holmes, R and Box, S, On the use of squeeze-film dampers in rotors support structures. Machine Vibration, 1992, Springer-Verlag London Limited, pp.71-79

6. Knight, M.J, Evaluation and prediction of a squeeze film damper performance. Third Year Project Report, April 1988, Department of Mechanical Engineering, University of Southampton, UK.

7. Taylor, M.J, Investigation and determination of the damping capacity of squeeze film dampers. M.Eng Third Year Project Report 1995/6, Report no. SP80: 95/96, May 1996, Department of Mechanical Engineering, University of Southampton, UK.

8. Levesley, M. Application of linearisation techniques to non-linear squeeze film isolator performance. Transfer thesis, Report no. ME/90/04, March 1990, Department of Mechanical Engineering, University of Southampton, UK.

9. Chu, F. and Holmes, R. The effect of squeeze film damper parameters on the unbalance response and stability of a flexible rotor. ASME Trans., J. Engineering Gas Turbine and Power, 1998, vol.120, pp.140148.

10. Chu. F. The vibration control of a flexible rotor by means of a squeeze film damper. Department of Mechanical Engineering, University of Southampton. PhD Thesis. Nov 1993.

11. Burghardt M. An investigation of the squeeze film damper of a super-critical rotor. Institute of Sound and Vibration Research, University of Southampton. MSc Dissertation. Dec 1998.

12. Siew, C. C., Hill, M., Holmes, R. and Brennan, M. J. A theoretical and experimental investigation into the vibration response of a flexible rotor and squeeze film damper assembly. Proc. Instn Mech Engrs. Part C, Journal of Mechanical Engineering Science, 2001, Vol 215, pp.1251-1270. 
13. Dede M.M, Dogan M, Holmes R. The damping capacity of sealed squeeze film bearing. ASME Trans., J. Tribology, July 1985, vol.107, pp. 411-418.

14. Davies, P.B. A general analysis of multi-recess hydrostatic journal bearing. Proc. Instn. Mech Engrs. Part I, 1969-70, 184 (43), pp.827-838.

15. Choy, K.C. and Halloran, J.D. Application of Hydrostatic Squeeze film dampers. ASLE Trans. Vol.25, 2, 1981, pp.245-251.

16. Rowe W.B. Advances in hydrostatic and hybrid bearing technology. Proc. Instn. Mech Engrs., Part C. J. of Mechanical Engineering Science, vol.203, 1989,pp.225-242.

17. Chen, P.Y.P and Hahn, E.J. Pressure distribution in squeeze film dampers with oil hole feed. Proc. Instn. Mech Engrs, Part J: J. of Engineering Tribology, vol.208,1994,pp.105-112.

18. Wang. J and Hahn, E.J. Transient Analysis of squeeze-film dampers with oil hole feed. Tribology Trans. Vol.38 (1995), 4, pp.837-844.

19. Wang, J. and Hahn, E.J. An experimental evaluation of squeeze-film dampers with groove and hole feed. Trans. of Mechanical Engineering, IEAust, vol.ME20,No.2, July 1995,pp.91-97.

20. Thompson W.T. Theory of vibration with applications. $2^{\text {nd }}$ Edition, George Allen \& Unwin, 1981.

21. Hatter, D. J. Matrix computer methods of vibration analysis. 1973, London Butterworths \& Co. (Publishers) Ltd.

22. Levesley M.C and Holmes R. The effect of oil supply and sealing arrangements on the performance of squeeze film dampers: An experimental study. Proc. Instn Mech Engrs. vol. 210, 1996. pp. 221-232.

23. Arauz G.L and SanAndres L. Effect of a circumferential feeding groove on the dynamic force response of a short squeeze film damper. ASME. Trans., J. Tribology, April 1994, vol.116. 
24. Levesley M.C and Holmes. R. Experimental investigation into the vibration response of an aero-engine rotor-damper assembly. Proc. Instn. Mech. Engrs., J. Aerospace Engineering, vol.208, Part G,1994, pp.5266.

25. Levesley, M.C. and Holmes, R. Influence of various parameters on the non-linear behaviour of a flexible shaft incorporating an uncentralized squeeze-film damper. Instn. Mech. Engrs Conference Transactions, $7^{\text {th }}$ International Conference on Vibrations in Rotating Machinery, 12-14 Sep 2000, University of Nottingham, UK. C576/104/2000, 509-521. 


\section{Captions}

Fig.1 Schematic diagrams of a SFD

Fig.2 Schematic diagram of the non-rotating SFD (Test Rig No.1)

Fig.3 Schematic diagram of the flexible-shaft incorporated with a SFD

(Test Rig No.2)

Fig.4 Comparison of predicted and experimental response of the non-rotating SFD (Table 2)

(Test No.1: $\mathrm{c}_{g} / \mathrm{c}=3.27, \mu=0.015 \mathrm{~Pa}-\mathrm{s}$ )

Fig.5 Comparison of predicted and experimental response of the non-rotating SFD (Table 2)

(Test No.2: $c_{g} / c=10.09, \mu=0.015 \mathrm{~Pa}-\mathrm{s}$ )

Fig.6 Comparison of predicted and experimental response of the non-rotating SFD (Table 2)

(Test No.3: $c_{g} / c=10.09, \mu=0.006 \mathrm{~Pa}-s$ )

Fig.7 Experimentally determined static fluid stiffness of the non-rotating SFD (Table 2)

(a) Test No.2: $c_{g} / c=10.09, \mu=0.015 \mathrm{~Pa}-\mathrm{s}$

(b) Test No.3: $c_{g} / c=10.09, \mu=0.006 \mathrm{~Pa}-\mathrm{s}$

Fig.8 Comparison of predicted and experimental response of the non-rotating SFD (Table 2)

(a) Test No.2: $c_{g} / c=10.09, \mu=0.015 \mathrm{~Pa}-\mathrm{s}, F_{a}=50 \mathrm{~N}$

(b) Test No 3: $c_{g} / c=10.09, \mu=0.006 \mathrm{~Pa}-\mathrm{s}, F_{a}=20 \mathrm{~N}$

(c) Test No 3: $c_{g} / c=10.09, \mu=0.006 \mathrm{~Pa}-\mathrm{s}, F_{a}=40 \mathrm{~N}$

Fig.9 Comparison of predicted and experimental response of the sprung SFD-flexible shaft assembly

(Table 4)(Test No.4 : $c_{g} / c=16.15, \mu=0.006 \mathrm{~Pa}-s$ )

Fig.10 Comparison of predicted and experimental responses of the sprung SFD-flexible shaft assembly (Table 4)

(Test No.5: $c_{g} / c=40.77, \mu=0.006 P a-s, R e=0.1228 \sim 1.5345$ )

Fig.11 Comparison of predicted and experimental responses of the sprung SFD-flexible shaft assembly (Table 4)

(Test No.6: $c_{g} / c=40.77, \mu=0.015 P a-s, R e=0.0508 \sim 0.6350$ )

Fig.12 Tangential and Radial Force Coefficients of Various Theoretical Models

(Note models $1 a-1 c$ do not predict a variation in radial force with $c_{g} / c$ ) 
Table 1 Dimensions of the non-rotating SFD

Table 2 Test conditions of the non-rotating SFD

Table 3 Dimensions of the SFD supporting the flexible shaft

Table 4 Testing conditions of the SFD supporting the flexible shaft

Table 5 Reynolds numbers and fluid inertia coefficients of the tests 

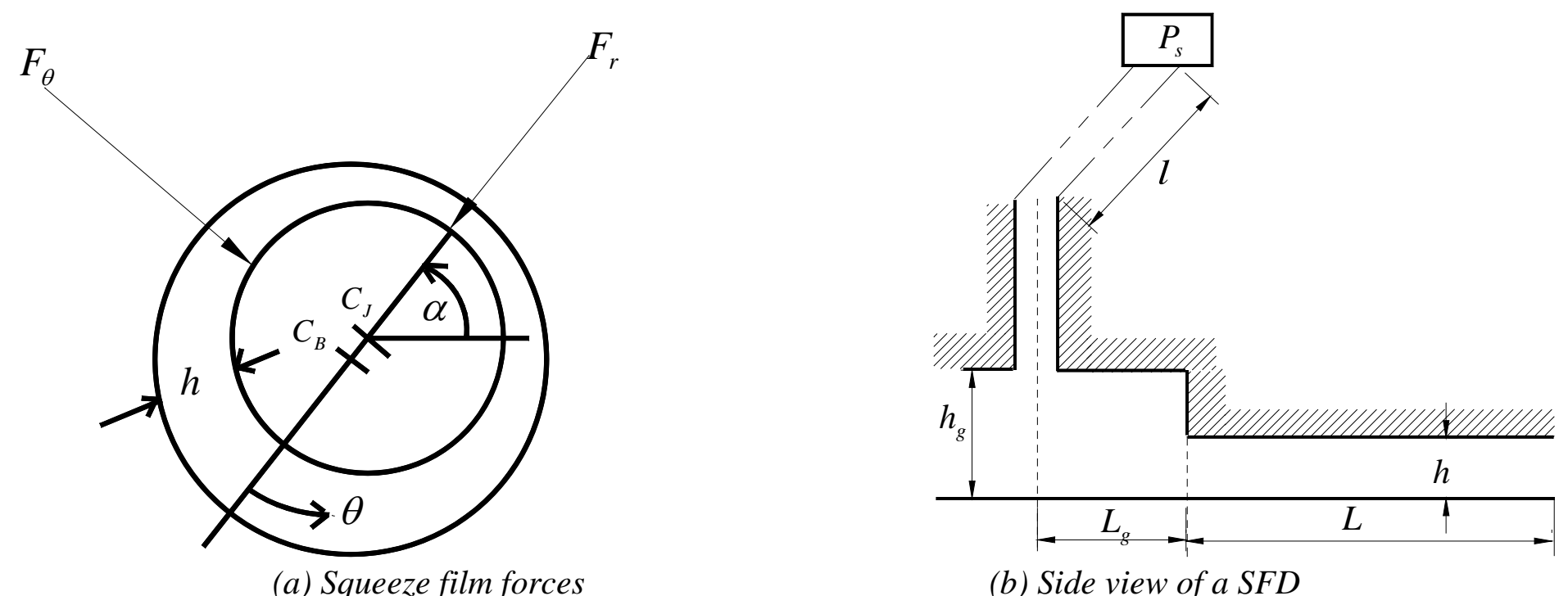

(b) Side view of a SFD 


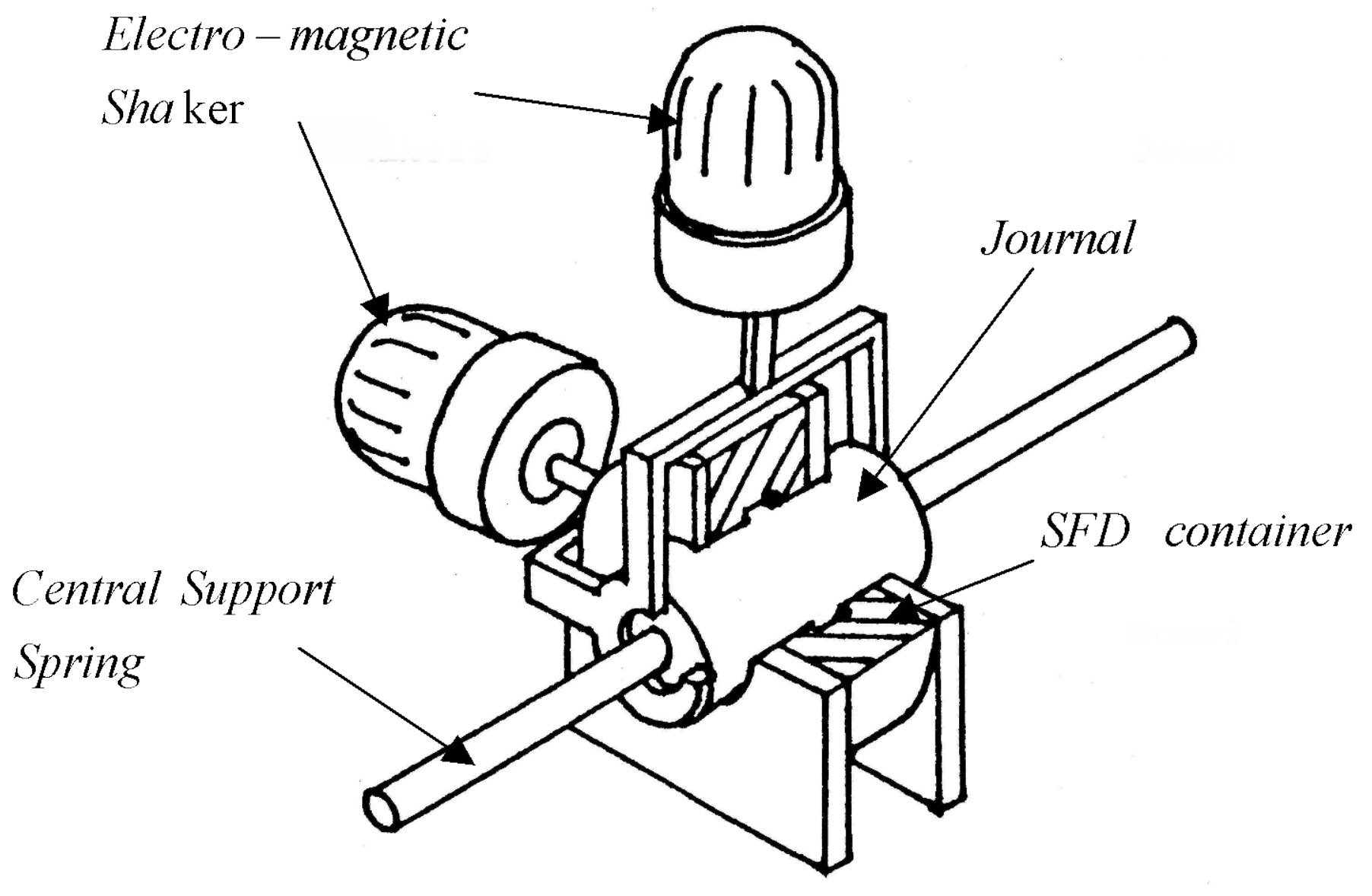




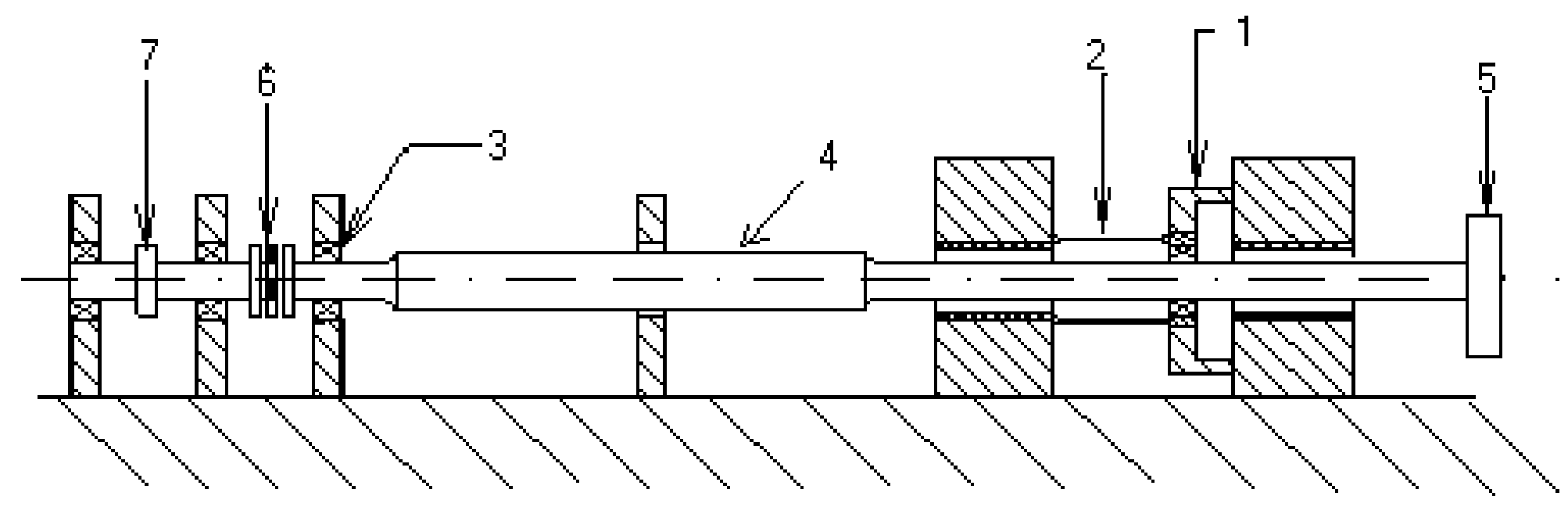

1. Squeeze film damper.

2. Retainer spring.

5. Unbalance mass on the disk.

3. Self-aligning bearing.

6. Flexible coupling

4. Flexible rotor

7. Pulley driven by motor 
(a) $\mathrm{Fa}=25 \mathrm{~N}$

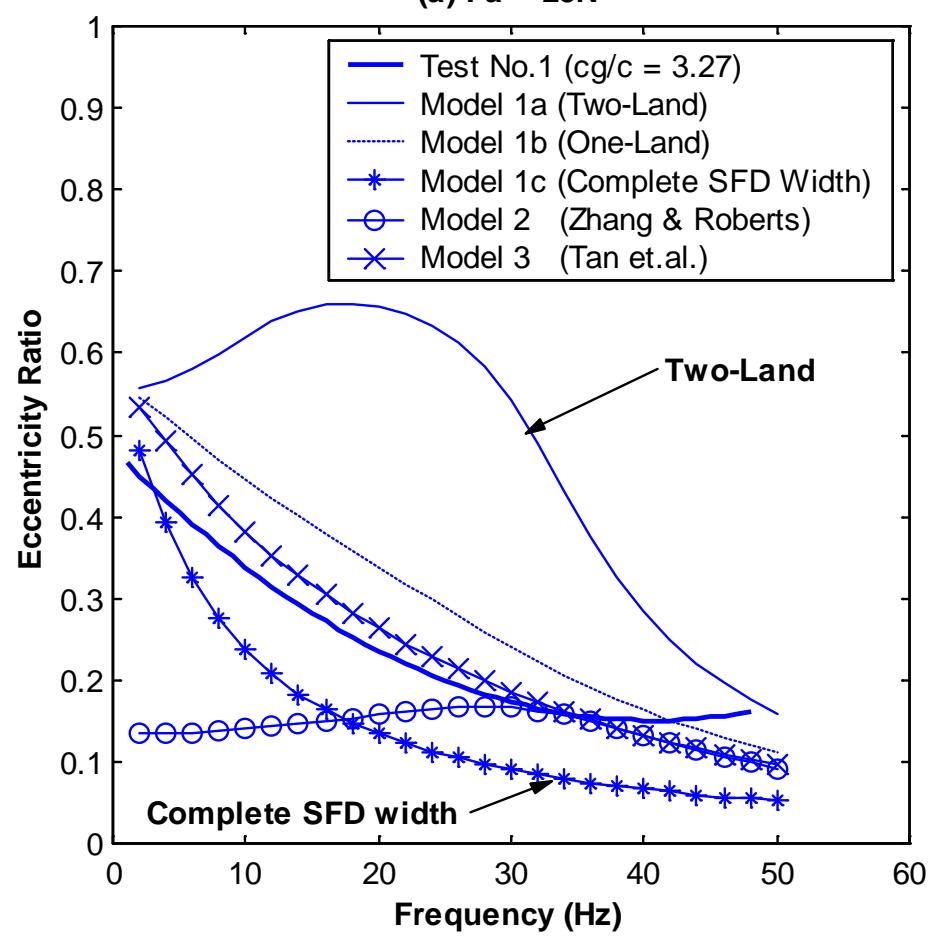

(b) $\mathrm{Fa}=50 \mathrm{~N}$

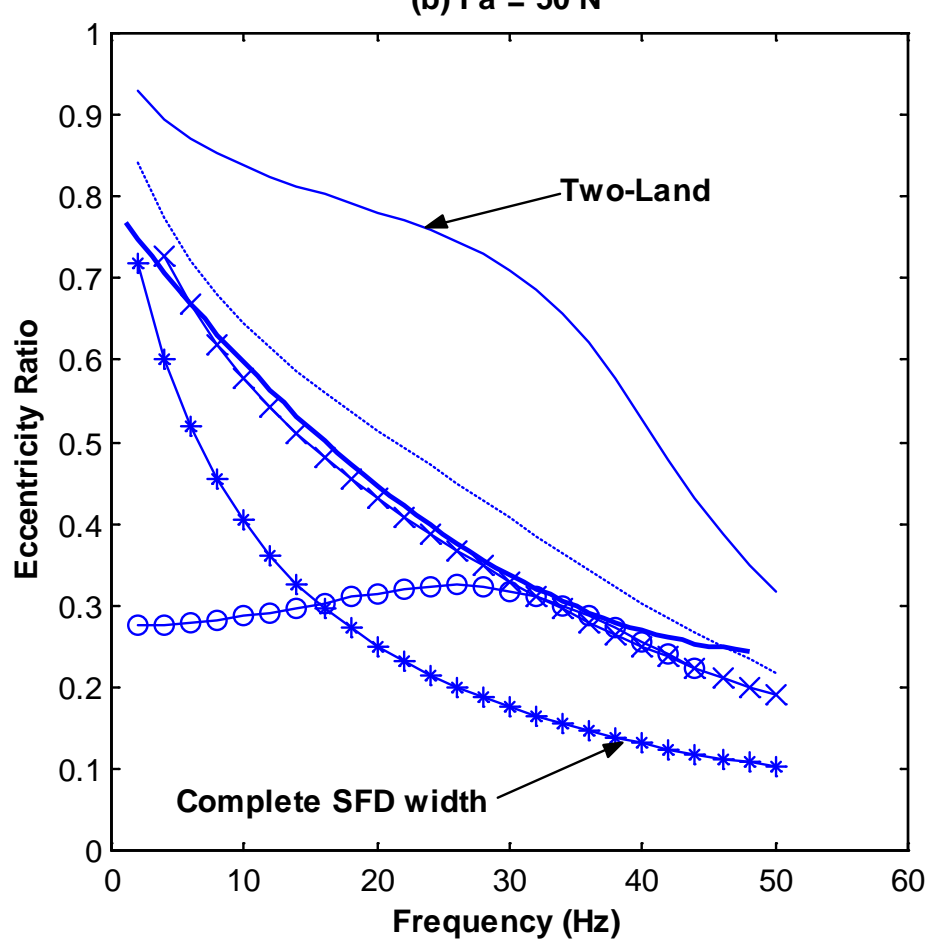


(a) $\mathrm{Fa}=25 \mathrm{~N}$

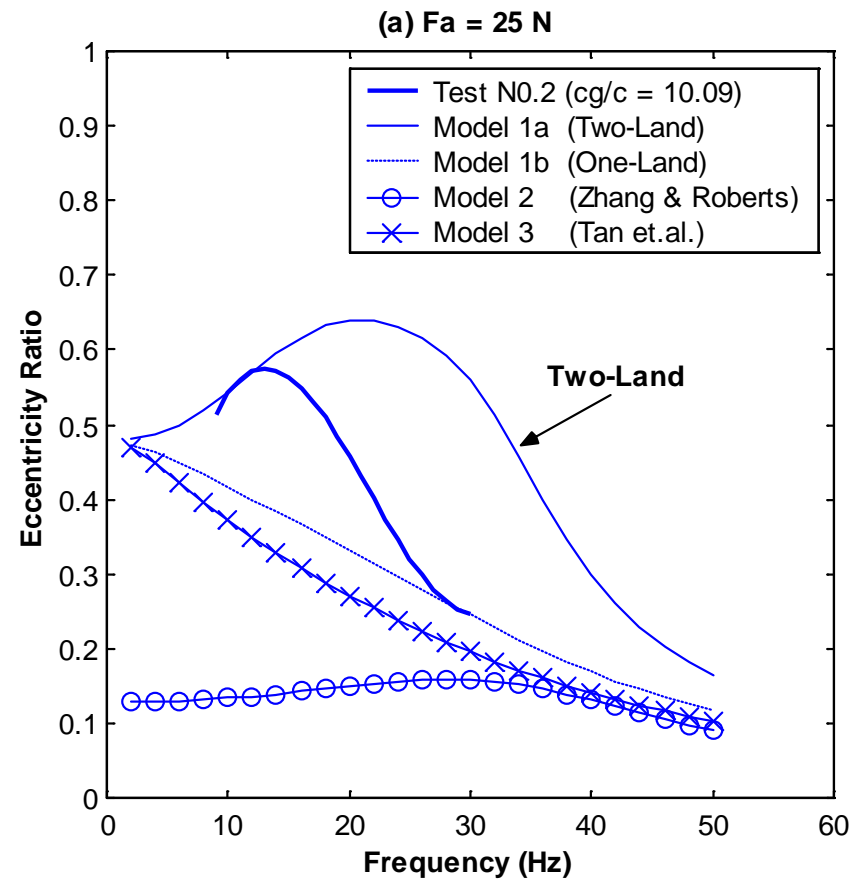

(b) $\mathrm{Fa}=50 \mathrm{~N}$

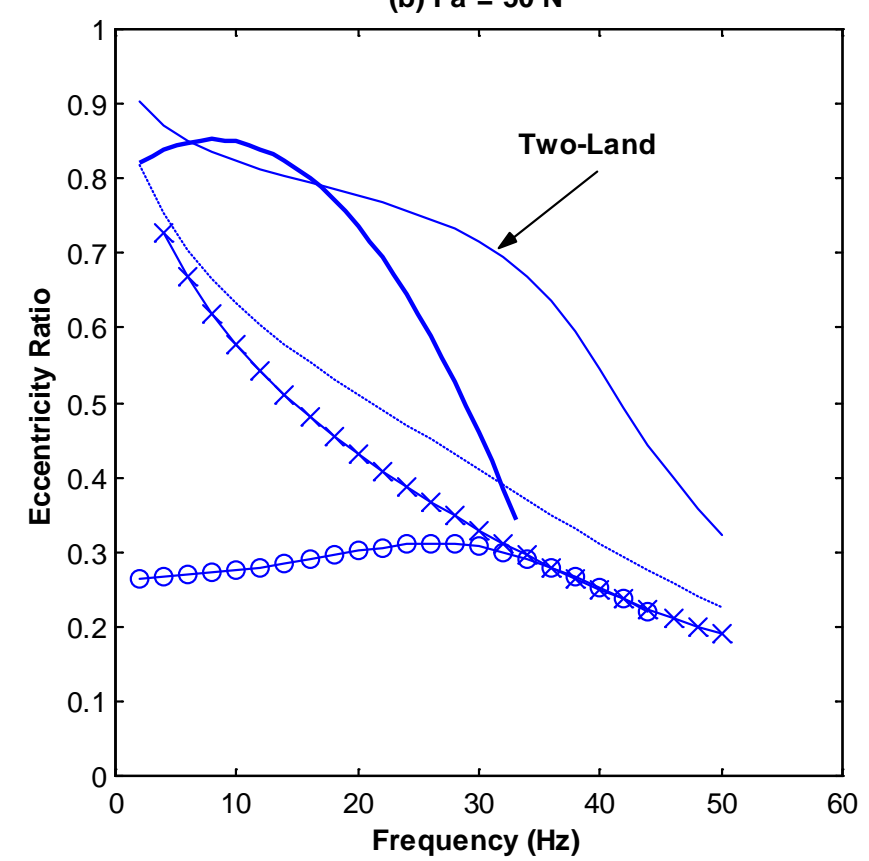


(a) $\mathrm{Fa}=20 \mathrm{~N}$

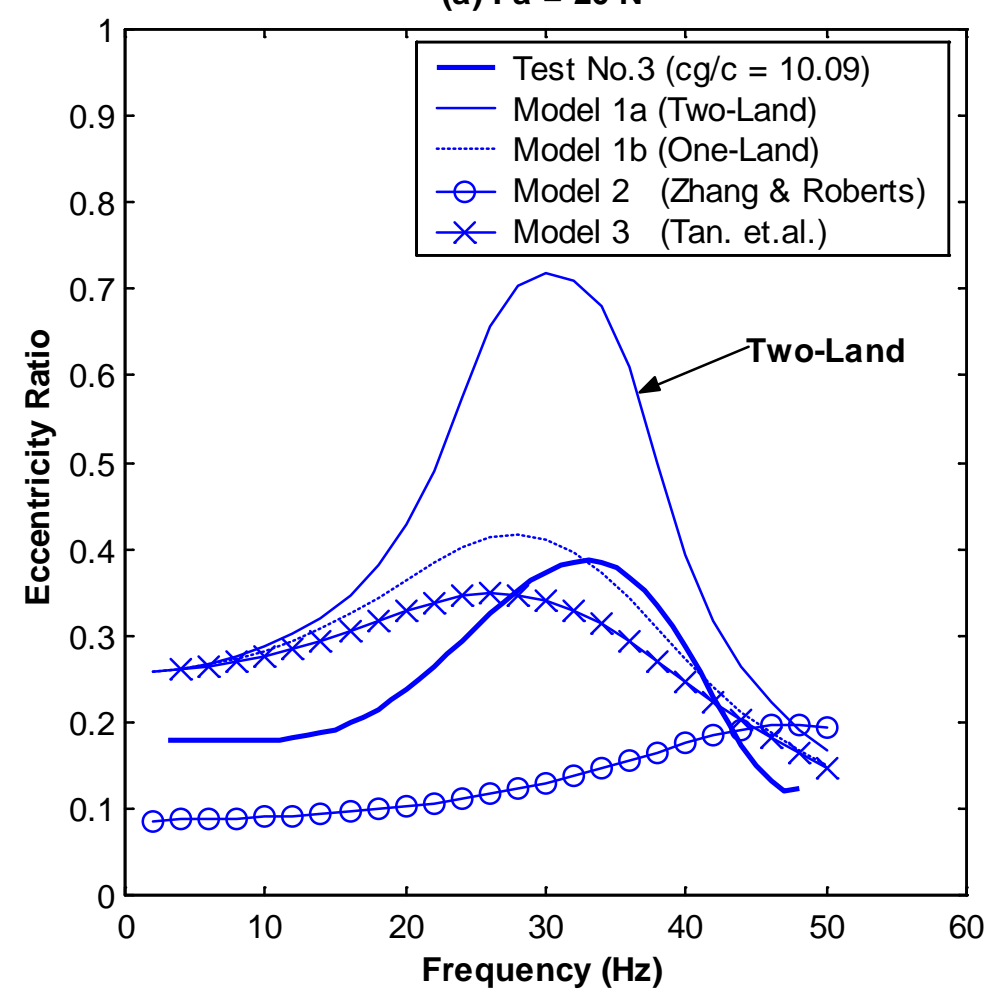

(b) $\mathrm{Fa}=40 \mathrm{~N}$

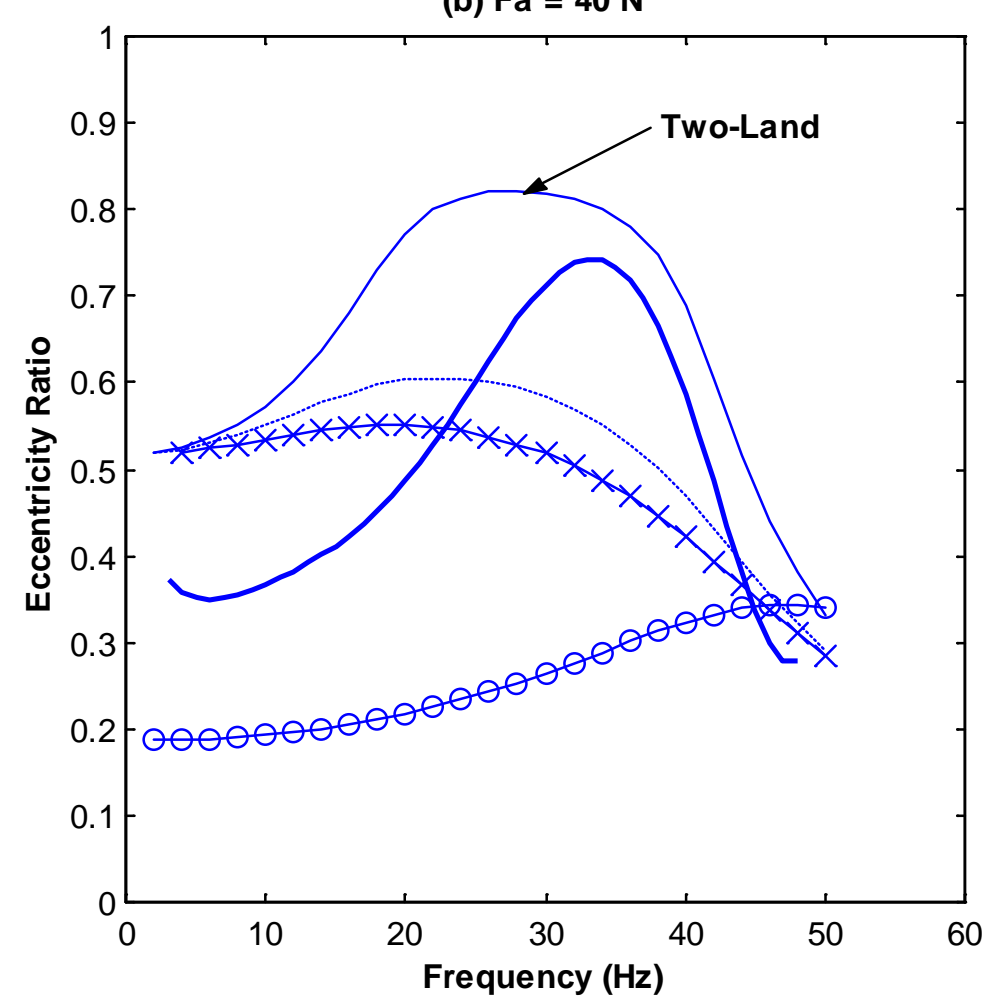



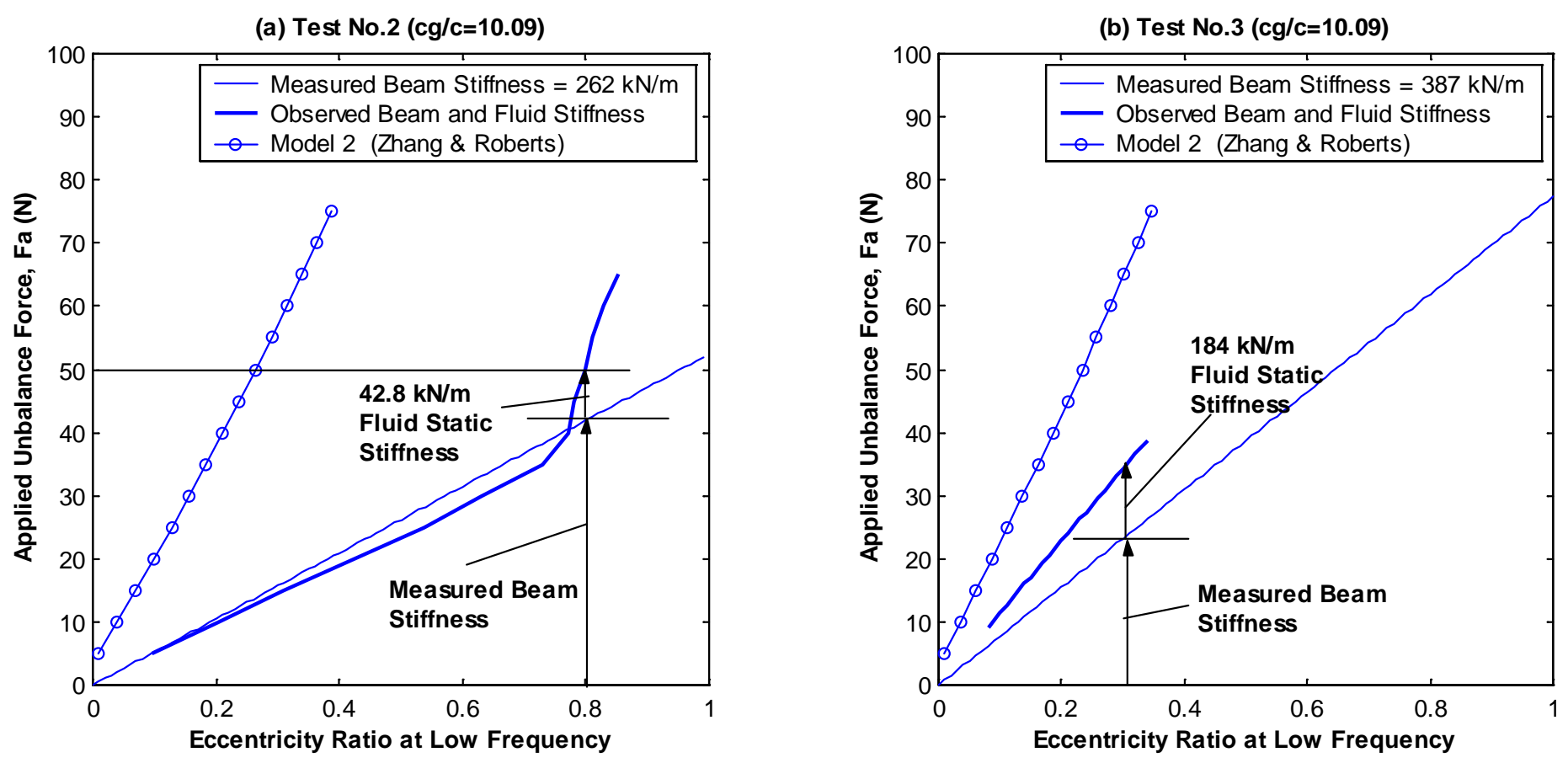

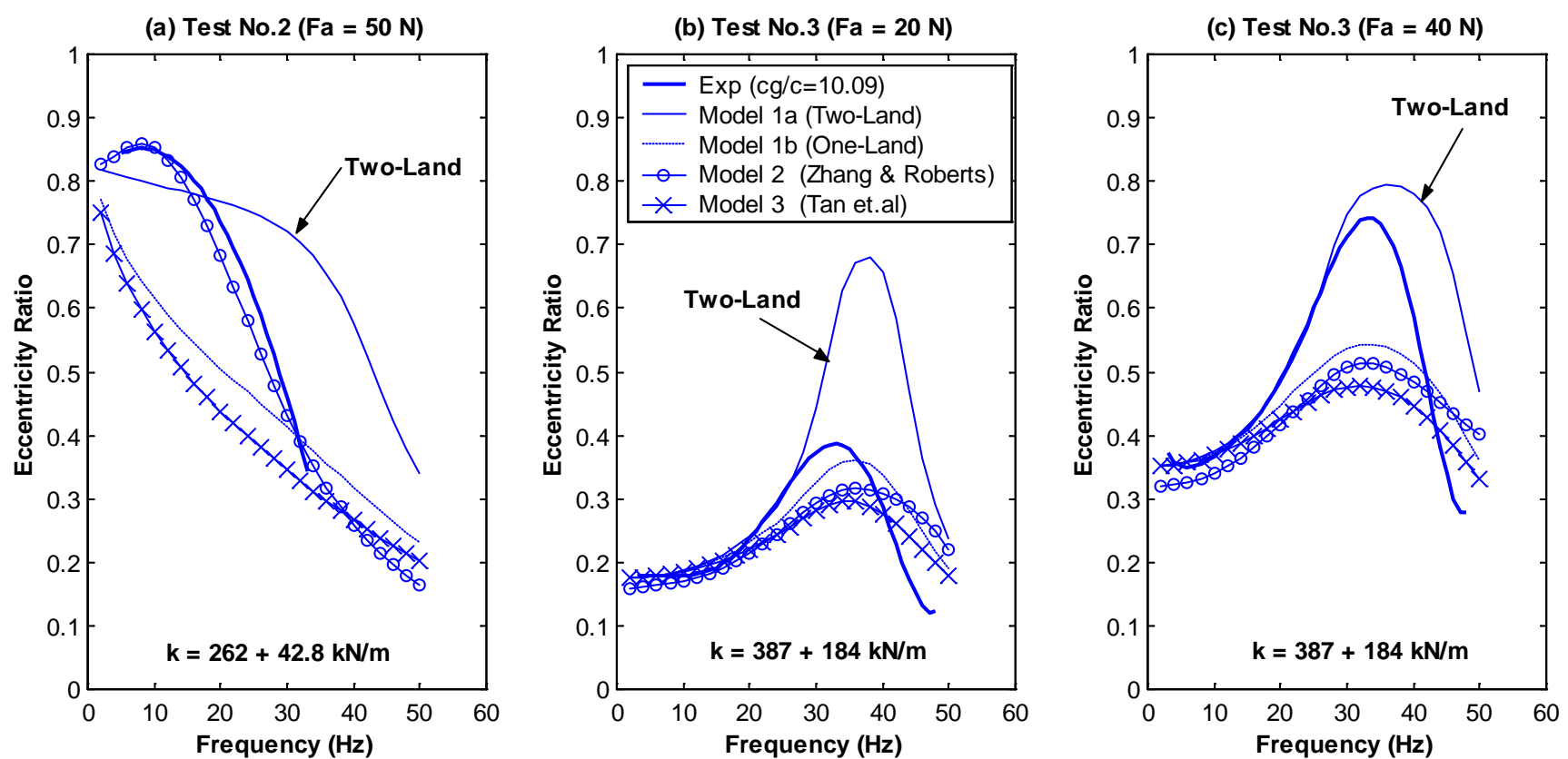
(a) $M_{u}=2.59 \mathrm{e}-4 \mathrm{kgm}$

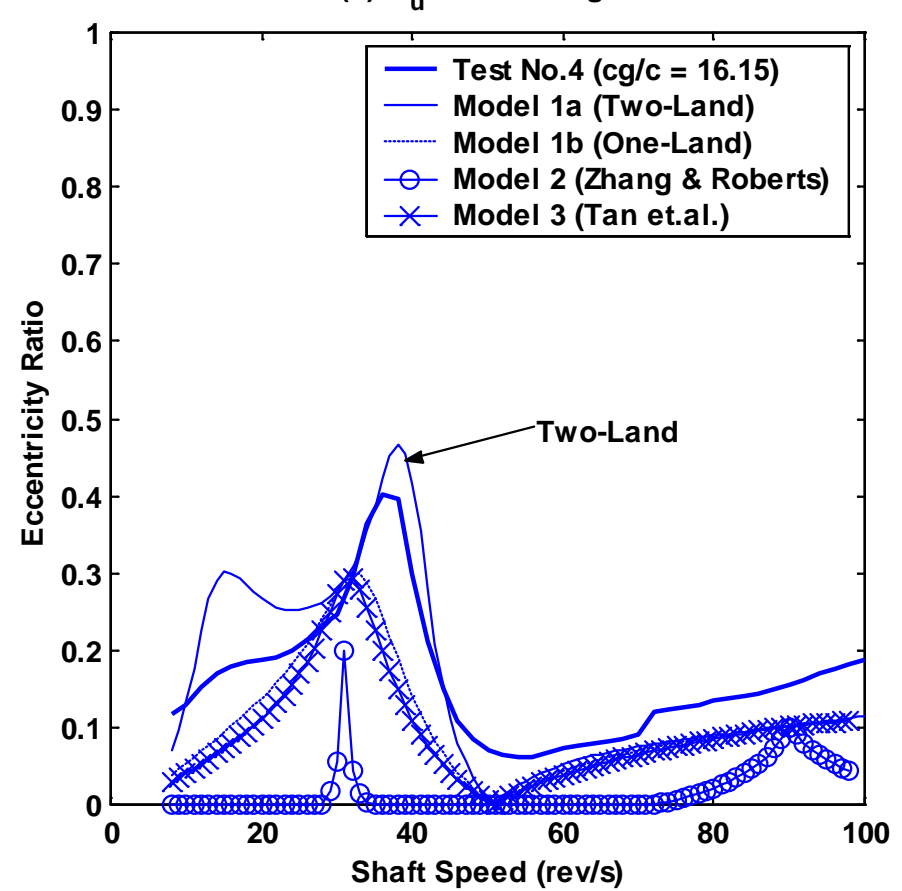

(b) $M_{u}=5.1 \mathrm{e}-4 \mathrm{kgm}$

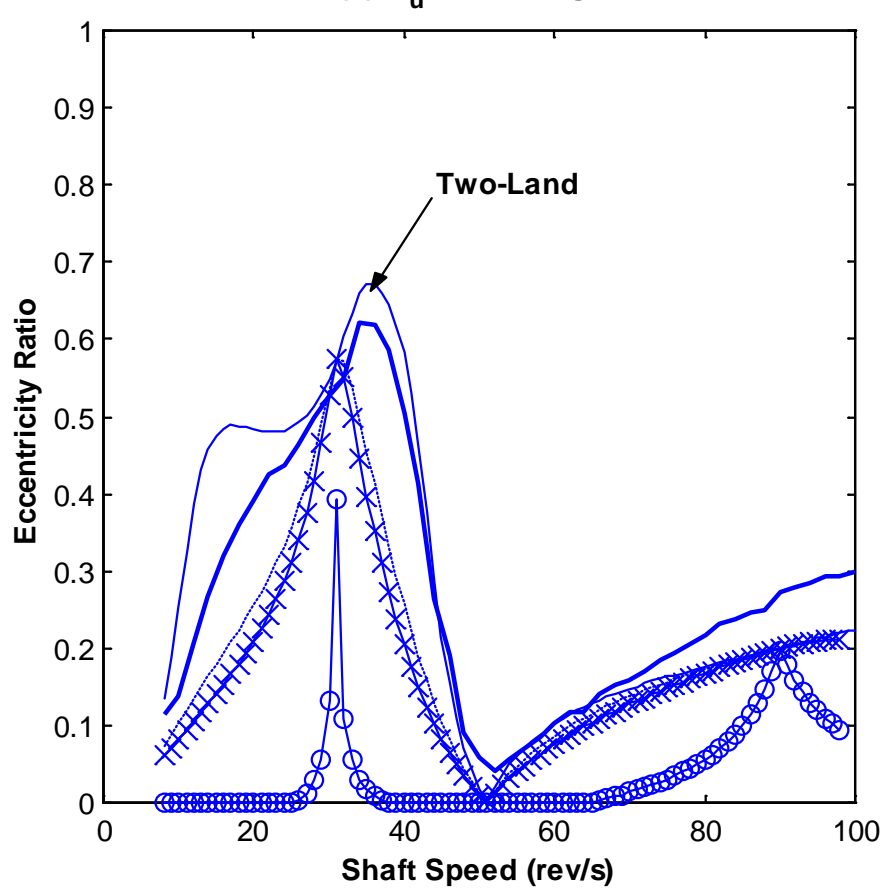


(a) $\mathrm{M}_{u}=2.59 \mathrm{e}-4 \mathrm{kgm}$

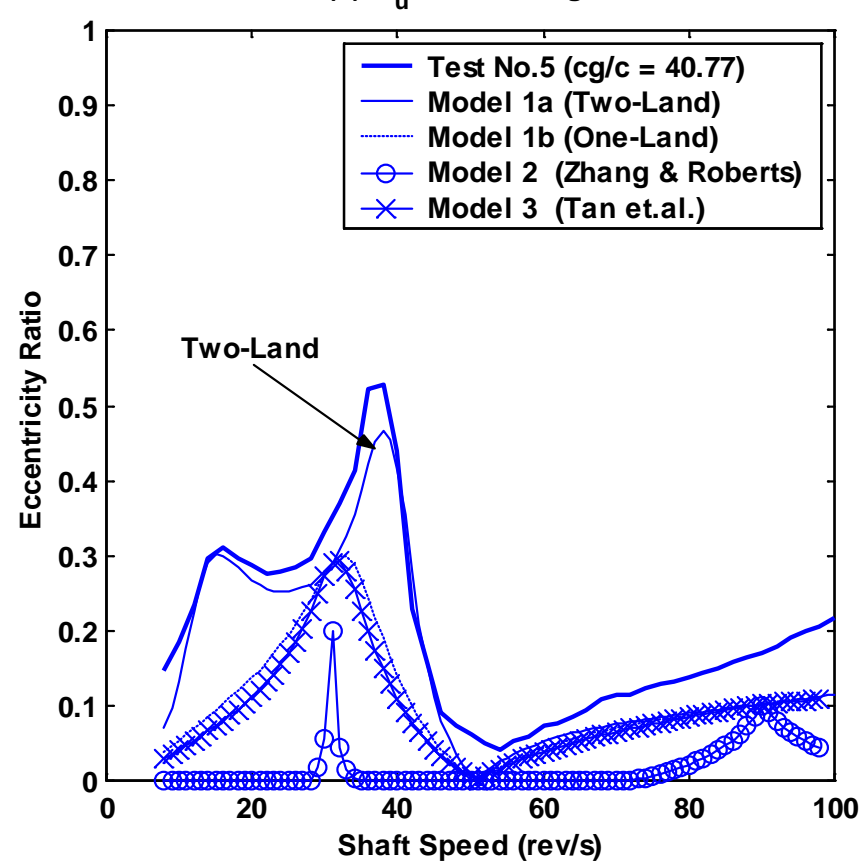

(b) $M_{u}=5.1 \mathrm{e}-4 \mathrm{kgm}$

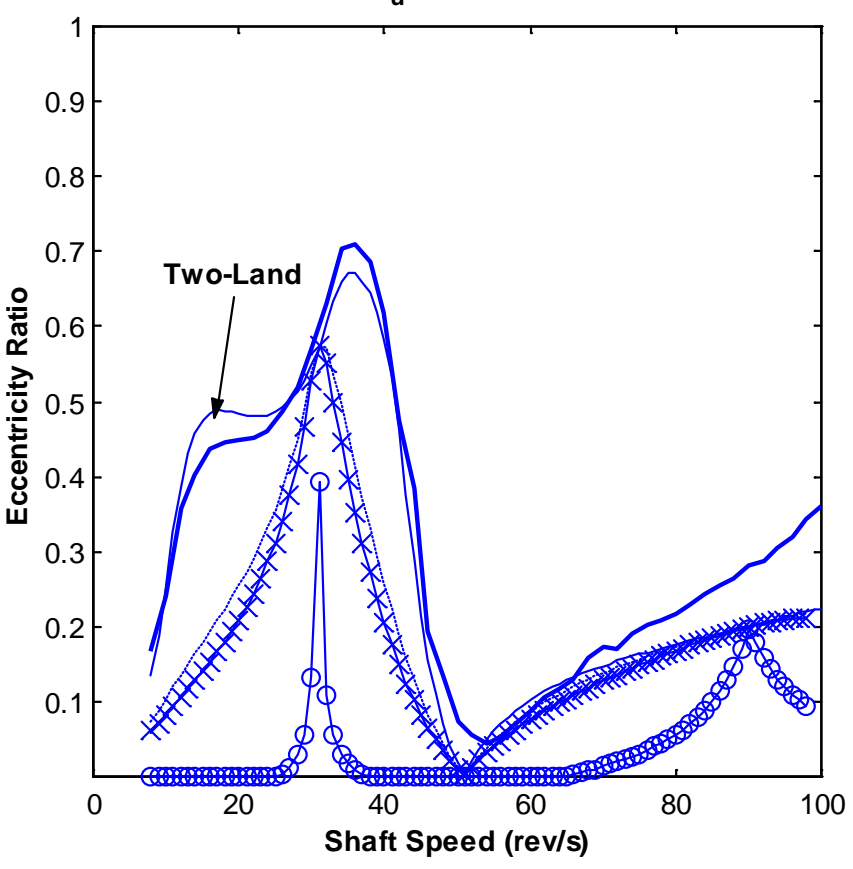



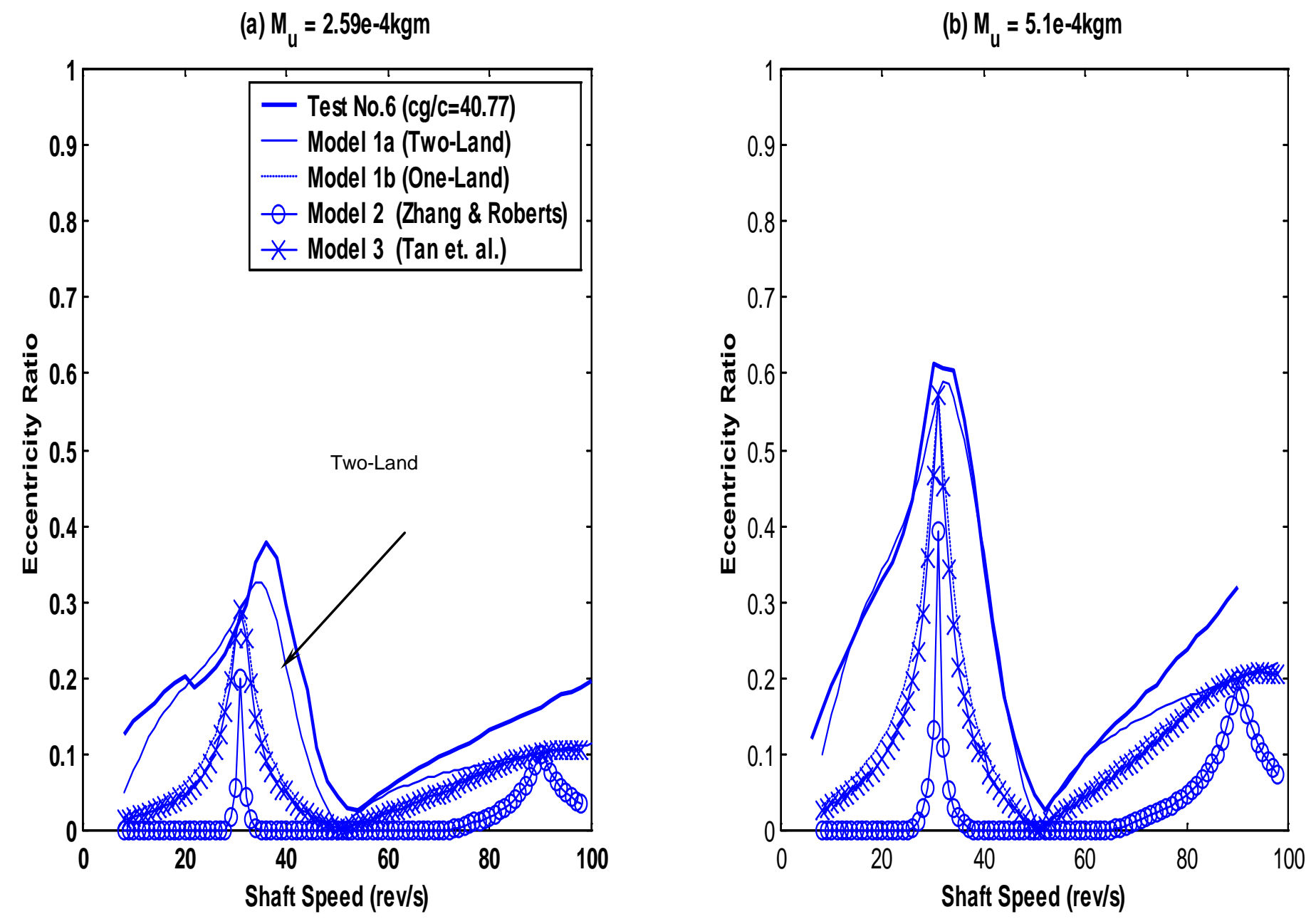

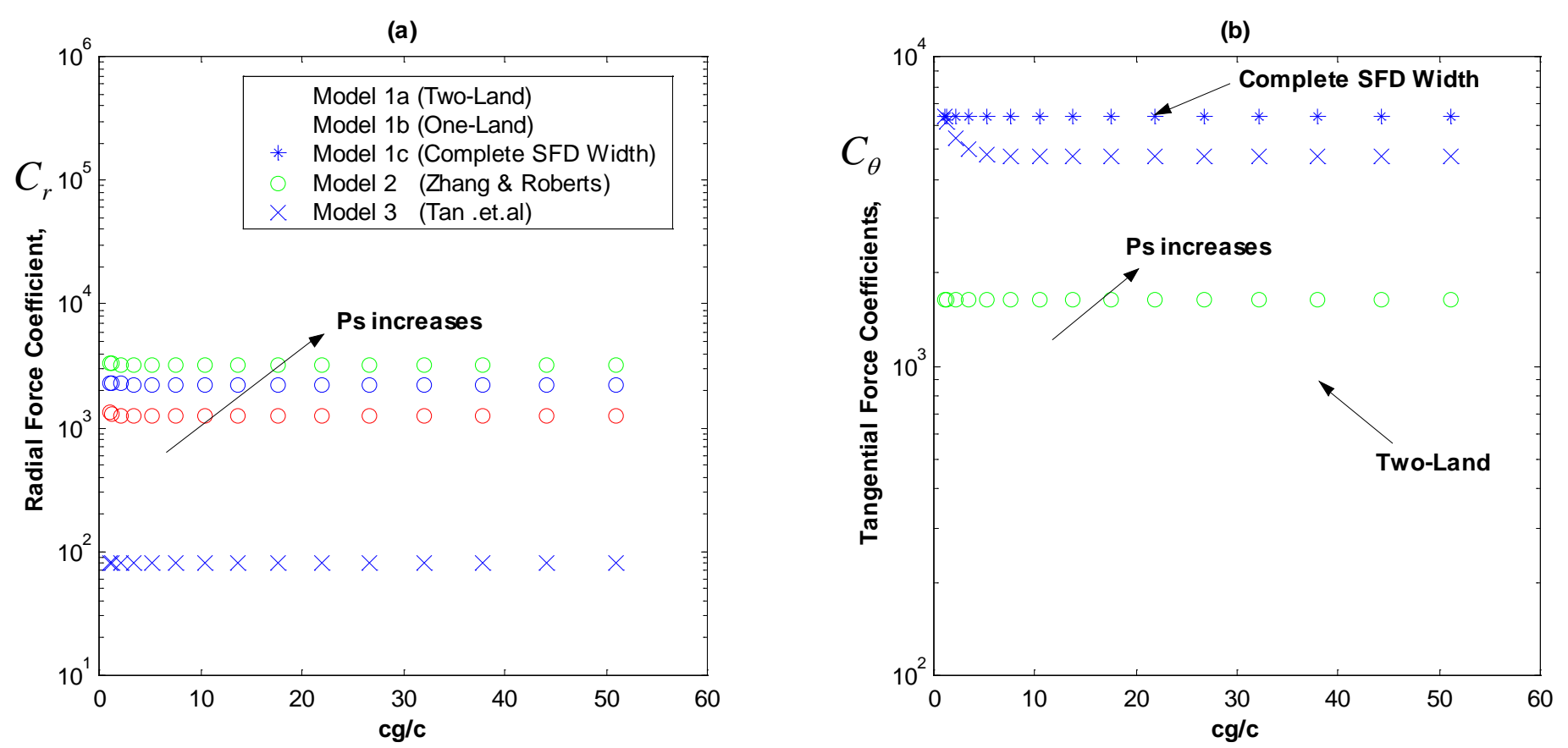


\begin{tabular}{|c|c|c|}
\hline Journal Radius $(R)=68.1 \mathrm{~mm}$ & Land Length $(L)=9.1 \mathrm{~mm}$ & $\begin{array}{c}\text { Oil Pipe Radius }(r) \\
=2.15 \mathrm{~mm}\end{array}$ \\
\hline $\begin{array}{c}\text { Radial Clearance }(C) \\
=0.22 \mathrm{~mm}\end{array}$ & Groove Length $\left(L_{g}\right)=1.9 \mathrm{~mm}$ & $\begin{array}{c}\text { Length of the Oil Pipes } \\
(l)=1.563 \mathrm{~m}\end{array}$ \\
\hline
\end{tabular}




\begin{tabular}{|c|c|c|c|c|c|c|c|c|}
\hline $\begin{array}{l}\text { Test } \\
\text { No. }\end{array}$ & $\begin{array}{c}\text { Beam } \\
\text { Stiffness } \\
(k) \\
\mathbf{k N} / \mathbf{m}\end{array}$ & $\begin{array}{c}\text { Effective } \\
\text { Mass } \\
(m) \\
\text { kg }\end{array}$ & $\begin{array}{c}\text { Supply } \\
\text { Pressure } \\
\left(P_{s}\right) \\
\text { kPa }\end{array}$ & $\begin{array}{c}\text { Oil } \\
\text { Viscosity } \\
(\mu) \\
\text { Pa-s }\end{array}$ & $\begin{array}{c}\text { Oil } \\
\text { Density } \\
(\rho) \\
\mathbf{k g} / \mathbf{m}^{3}\end{array}$ & $\begin{array}{c}\text { Applied } \\
\text { Force } \\
\left(F_{a}\right) \\
\mathbf{N}\end{array}$ & $\begin{array}{c}\text { Groove } \\
\text { Depth } \\
\left(C_{g}\right) \\
\text { mm }\end{array}$ & $\begin{array}{c}\text { Groove } \\
\text { Depth-to } \\
\text { Clearance } \\
\text { Ratio } \\
\left(C_{g} / C\right)\end{array}$ \\
\hline 1 & 225 & 10.40 & 68.95 & 0.015 & 870 & 25,50 & 0.72 & 3.27 \\
\hline 2 & 262 & 10.14 & 68.95 & 0.015 & 870 & 25,50 & 2.22 & 10.09 \\
\hline 3 & 387 & 9.95 & 68.95 & 0.006 & 841 & 20,40 & 2.22 & 10.09 \\
\hline
\end{tabular}




\begin{tabular}{|l|l|l|}
\hline Journal Radius $(R)=50 \mathrm{~mm}$ & Land Length $(L)=9.72 \mathrm{~mm}$ & $\begin{array}{l}\text { Oil Pipe Radius }(r) \\
=1.5 \mathrm{~mm}\end{array}$ \\
\hline $\begin{array}{l}\text { Radial Clearance }(C) \\
=0.132 \mathrm{~mm}\end{array}$ & Groove Length $\left(L_{g}\right)=1.9 \mathrm{~mm}$ & $\begin{array}{l}\text { Length of the Oil Pipes } \\
(l)=1.44 \mathrm{~m}\end{array}$ \\
\hline
\end{tabular}




\begin{tabular}{|c|c|c|c|c|c|c|}
\hline $\begin{array}{l}\text { Test } \\
\text { No. }\end{array}$ & $\begin{array}{c}\text { Supply } \\
\text { Pressure } \\
\left(P_{s}\right) \\
\text { kPa }\end{array}$ & $\begin{array}{c}\text { Oil } \\
\text { Viscosity } \\
(\mu) \\
\text { Pa-s }\end{array}$ & $\begin{array}{c}\text { Oil } \\
\text { Density } \\
(\rho) \\
\mathbf{k g} / \mathbf{m}^{3}\end{array}$ & $\begin{array}{c}\text { Unbalance mass, } \\
\qquad\left(M_{u}\right) \\
\text { kgm }\end{array}$ & $\begin{array}{c}\text { Groove } \\
\text { Depth }\left(c_{g}\right) \\
\text { mm }\end{array}$ & $\begin{array}{c}\text { Groove } \\
\text { Depth-to } \\
\text { Clearance } \\
\text { Ratio }\left(C_{g} / c\right)\end{array}$ \\
\hline 4 & 120 & 0.006 & 841 & 2.59e-4, 5.1e-4 & 2.132 & 16.15 \\
\hline 5 & 120 & 0.006 & 841 & $2.59 \mathrm{e}-4,5.1 \mathrm{e}-4$ & 5.382 & 40.77 \\
\hline 6 & 120 & 0.015 & 870 & $2.59 \mathrm{e}-4,5.1 \mathrm{e}-4$ & 5.382 & 40.77 \\
\hline
\end{tabular}




\begin{tabular}{|c|c|c|c|c|c|c|}
\hline Test No. & $\mathbf{1}$ & $\mathbf{2}$ & $\mathbf{3}$ & $\mathbf{4}$ & $\mathbf{5}$ & $\mathbf{6}$ \\
\hline $\begin{array}{c}\text { Reynolds } \\
\text { Number at } \\
\text { the land } \\
\left(\operatorname{Re}_{\mathrm{L}}\right)\end{array}$ & $0.017 \sim 0.889$ & $0.035 \sim 0.529$ & $0.085 \sim 2.131$ & $0.122 \sim 1.534$ & $0.122 \sim 1.534$ & $0.050 \sim 0.635$ \\
\hline $\begin{array}{c}\text { Reynolds } \\
\text { number at } \\
\text { the groove } \\
\left(\operatorname{Re}_{q}\right)\end{array}$ & $0.188 \sim 9.445$ & $1.796 \sim 62.861$ & $8.686 \sim 217.02$ & $32.03 \sim 400.31$ & $204.08 \sim 2.551 \times 10^{3}$ & $84.447 \sim 1.05 \times 10^{3}$ \\
\hline $\begin{array}{c}\text { Inertia } \\
\text { Coefficient } \\
\left(M_{\text {rcen }}\right) \\
\text { kg }\end{array}$ & $0.315 \sim 0.506$ & $0.236 \sim 0.480$ & $0.28 \sim 0.498$ & $0.4307 \sim 0.608$ & $0.409 \sim 0.609$ & $0.409 \sim 0.631$ \\
\hline
\end{tabular}

